San Jose State University

SJSU ScholarWorks

Master's Theses

Master's Theses and Graduate Research

Summer 2012

\title{
The Effectiveness of Glare-Obscuring Glasses on Nighttime Driving Performance
}

Heath Theodore Friedland

San Jose State University

Follow this and additional works at: https://scholarworks.sjsu.edu/etd_theses

\section{Recommended Citation}

Friedland, Heath Theodore, "The Effectiveness of Glare-Obscuring Glasses on Nighttime Driving Performance" (2012). Master's Theses. 4194.

DOI: https://doi.org/10.31979/etd.byjp-34sm

https://scholarworks.sjsu.edu/etd_theses/4194

This Thesis is brought to you for free and open access by the Master's Theses and Graduate Research at SJSU ScholarWorks. It has been accepted for inclusion in Master's Theses by an authorized administrator of SJSU ScholarWorks. For more information, please contact scholarworks@sjsu.edu. 


\title{
THE EFFECTIVENESS OF GLARE-OBSCURING GLASSES ON NIGHTTIME DRIVING PERFORMANCE
}

\author{
A Thesis \\ Presented to \\ San José State University \\ In Partial Fulfillment \\ of the Requirements for the Degree \\ Master of Science
}

The Faculty of the Graduate Program in Human Factors and Ergonomics

by

Heath T. Friedland

August 2012 
(C) 2012

Heath T. Friedland

ALL RIGHTS RESERVED 
The Designated Thesis Committee Approves the Thesis Titled

\title{
THE EFFECTIVENESS OF GLARE-OBSCURING GLASSES ON NIGHTTIME DRIVING PERFORMANCE
}

\author{
by \\ Heath T. Friedland \\ APPROVED FOR THE GRADUATE PROGRAM IN HUMAN FACTORS AND \\ ERGONOMICS \\ SAN JOSÉ STATE UNIVERSITY
}

August 2012

Dr. Sean Laraway

Dr. Louis Freund

Dr. Cary Feria
Department of Psychology

Department of Industrial \& Systems Engineering

Department of Psychology 


\title{
ABSTRACT \\ THE EFFECTIVENESS OF GLARE-OBSCURING GLASSES ON NIGHTTIME DRIVING PERFORMANCE
}

\author{
by Heath T. Friedland
}

Currently no driver-aid system effectively addresses glare-reduction for oncoming headlights. Glare at night has the ability to decrease our visual acuity and cause discomfort or pain. This decreased visual ability constitutes an increased risk for driver error and a potential roadway safety hazard. The severity of these detrimental effects has previously been shown to increase with driver age and is thought to be further exacerbated by the increased brightness of High Intensity Discharge (HID) headlights.

In the current study, the effects of headlight glare from HID and halogen lights on driver performance was examined in a custom driving simulator. A novel polarized headlight glare-blocking system was also examined for its effectiveness in reducing headlight glare. Decreased visual field perception occurred across all age groups with the use of oncoming HID headlights compared to halogen headlights. In addition, older drivers' performance on the visual awareness task was significantly decreased as compared to their younger counterparts. The performance-restoring effects of the headlight-blocking system were especially beneficial to older adults exposed to HID headlights, restoring visual field perceptual abilities to nearly that of the younger age group. As even brighter LED-based headlights reach the automotive market in the midst of an expanding older driver population, it is urged that automotive manufacturers consider glare-mitigation strategies when designing current headlight systems. 


\section{ACKNOWLEDGEMENTS}

I would like to express my deepest gratitude to everyone who assisted in turning the concept for this thesis into a reality. I would like to thank my committee chair Dr. Sean Laraway for an outstanding amount of help with everything from the analysis to final edits, and everything in-between. When I came to you with the jumbled ball of yarn I called my data, you calmly and orderly untangled it in a way I could never have tackled on my own. This thesis never would have become a reality without your steadfast dedication and I am forever grateful. I would also like to sincerely thank my committee members Dr. Cary Feria and Dr. Louis Freund for their amazing diligence in supporting me through this process from conception to the final draft.

I would like to thank my parents RuthAnn and Myles Friedland for their unwavering support which sustained me through this process, beginning to end, assisting me in overcoming each of many hurdles that stood in my path. I was ready to throw in the towel many times throughout this process and you never let me. I would also like to thank my sister, Kimberly Friedland, who voluntarily jumped in to save the day in a time of crisis, spending countless hours gathering participants from around campus, in quantities I did not believe were possible. Without her last minute and unrelenting help this elaborate experiment would have sat silently waiting for participants that otherwise would not have arrived.

I would like to thank my best friend, Gabriel Reyes, for spending endless hours with me on the phone and in coffee shops while we battled through our theses together. Without his thoughtful insight and unrelenting encouragement to push forward I surely would have never made it to this stage. Thank you for helping me see the trees from the forest. I would also like to thank my good friend Daynan Burns, who assisted in much of the construction and setup of the experimental room, and who figured out solutions to fundamental problems we could never have foreseen. You made the difficult work of building the experimental setup an enjoyable one. I would also like to thank my friend Mariah Burns for seemingly years of help on nearly every aspect of this thesis, from putting up flyers and recruiting programmers around campus, to hanging countless feet of black curtains, to convincing me that I could, in fact, pull this off. Thank you for your patience, encouragement, and most importantly believing in me over the years. I would also like to thank the rest of the Burns family who did everything in their power to assist me in realizing my potential, and helping me reach my goals. I am forever indebted.

I would like to thank my friends and fellow students Katherine Spencer and Katie Atkinson for spending innumerable hours discussing the ins and outs of pulling off this thesis. Without you two I would have never made it to this point.

Finally, I would like to thank my faithful companion Beau, my Yellow Lab, who patiently stayed by my side throughout countless nights while I typed, edited, and pondered over this thesis.

Once again, thank you to all my family, friends, and professors for whom this paper is dedicated. Without your enduring support, patience, and encouragement this study would never have happened. I'm genuinely grateful. Thank you all for inspiring me to "go big." 


\section{Table of Contents}

Introduction 1

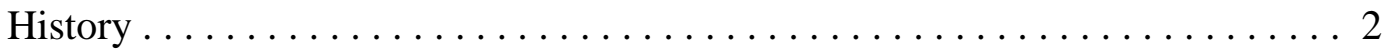

Glare and Age Concerns ........................ 8

Method 16

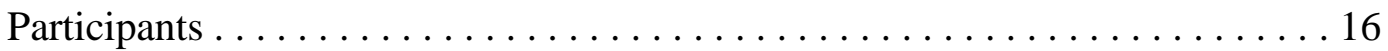

Apparatus .............................. 17

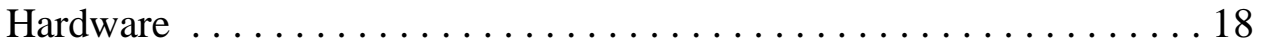

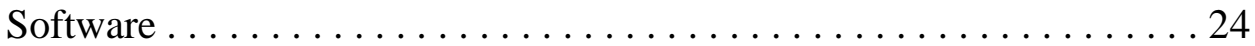

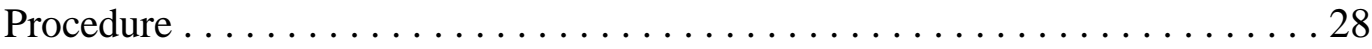

Dependent Variables and Data Analysis . . . . . . . . . . . . . . . 30

$\begin{array}{ll}\text { Results } & 32\end{array}$

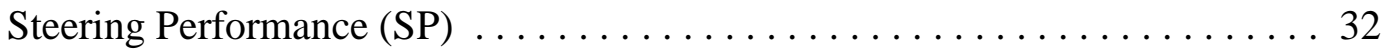

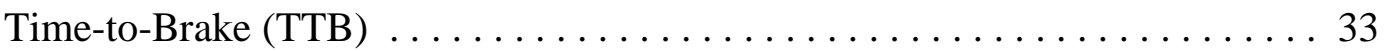

Time-to-Brake - False Positive $($ TTB-FP) $\ldots \ldots \ldots \ldots \ldots \ldots \ldots \ldots \ldots$

Visual Awareness (VA) . . . . . . . . . . . . . . . . . . . . . . 34

Visual Awareness - False Positive $($ VA-FP) . . . . . . . . . . . . . . . . . 40

$\begin{array}{ll}\text { Discussion } & 43\end{array}$

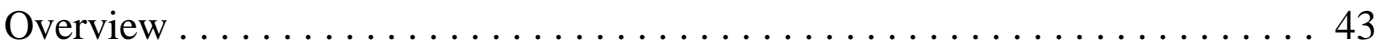

Specific Glare Effects . . . . . . . . . . . . . . . . . . . 44

Comparative Findings . . . . . . . . . . . . . . . . . . . . 48

Additional Age Effects . . . . . . . . . . . . . . . . . 54 


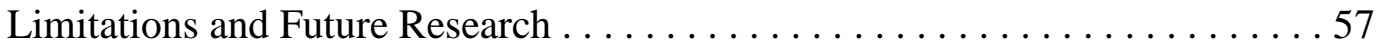

Implications for Practice $\ldots \ldots \ldots \ldots \ldots \ldots \ldots \ldots \ldots \ldots$

Closing Remarks .......................... 62

$\begin{array}{ll}\text { References } & 64\end{array}$

Appendix A - Consent Form $\quad 69$

Appendix B - Data Collection Forms $\quad 70$

Appendix C - Human Subjects Institutional Review Board Approval 73 


\section{List of Figures}

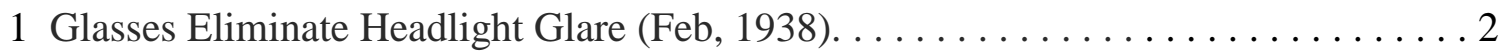

2 Simulated view of oncoming headlights with a polarized glare-blocking system $\ldots 15$

3 Participant in younger age group sitting in the experimental vehicle $\ldots \ldots \ldots \ldots$

4 Black paper curtains used to darken experimental area can be seen surrounding the

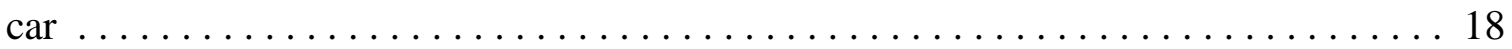

5 Headlights on moving conveyor belt simulating oncoming traffic . . . . . . . 19

6 Effect of opposed polarized filters on light transmittance $\ldots \ldots \ldots \ldots \ldots \ldots \ldots 21$

7 Comparison of light transmittance through in-phase (left) and out-of-phase (right)

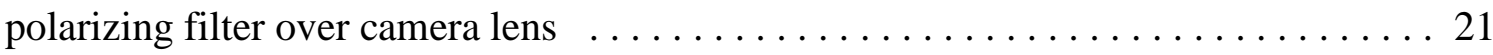

8 Installation of gyroscopic mouse into faux-airbag $\ldots \ldots \ldots \ldots \ldots \ldots \ldots \ldots \ldots \ldots$

9 Wireless mouse placed under brake pedal, with actuator arm attached to pedal . . . . 23

10 Screenshot of roadway produced by the simulator software $\ldots \ldots \ldots \ldots \ldots 24$

11 View of driving simulator from inside test vehicle $\ldots \ldots \ldots \ldots \ldots \ldots \ldots$

12 Screenshot of visual awareness (VA) task with artificial overlay grid illustrating

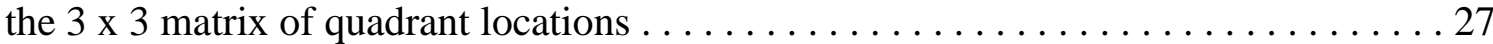

13 Participant wearing blue glare-blocking type glasses $\ldots \ldots \ldots \ldots \ldots \ldots$

14 Age differences in performance on steering task $\ldots \ldots \ldots \ldots \ldots \ldots \ldots \ldots \ldots \ldots$

15 Age difference in false-positive responses during braking task . . . . . . . . . 34

16 Performance differences with varied headlight type during visual awareness task . . 35

17 Performance differences with use of headlight-blocking system during visual

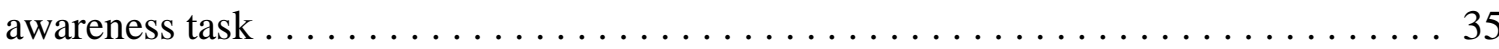


18 Performance differences in age group during the visual awareness task ...... 36

19 Two-way interaction between age and use of headlight-blocking system during

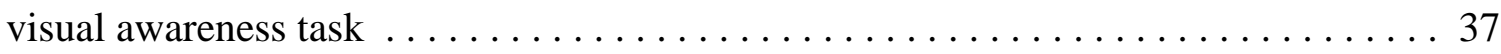

20 Two-way interaction between headlight type and use of headlight-blocking

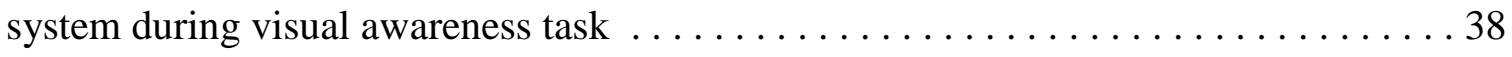

21 Three-way interaction between age, use of headlight-blocking system, and headlight type during visual awareness task $\ldots \ldots \ldots \ldots \ldots \ldots \ldots \ldots \ldots \ldots \ldots$

22 Differences in false-positive response rate for age groups during the visual awareness task ................................... 41 


\section{List of Tables}

1 Means for all variables and conditions $\ldots \ldots \ldots \ldots \ldots \ldots \ldots \ldots \ldots \ldots \ldots \ldots \ldots \ldots$ 


\section{Introduction}

The goals of automotive engineers, designers, and researchers are to improve both the driving experience and safety of the next generation of automobiles. At times in the development process these two objectives may be in conflict with each other. In these situations modifications are required to balance these two objectives. Within the realm of vehicle lighting, these two objectives are, in fact, diametrically opposed as a tradeoff exists between visibility for the driver of the car fitted with the lights and glare experienced by oncoming traffic. Interestingly, what increases visibility for one driver decreases visibility for another (National Highway Traffic Safety Administration, 2007). Recent concerns from government entities, research institutions, and the general public have increased as new high-intensity headlight technology begins to replace the previous lighting technology (Bullough et al., 2008).

As many of us have experienced during nighttime driving, the glare from oncoming headlights may be uncomfortable or even temporarily blinding. When the ratio of source light to background light intensity increases, glare is increased. Glare is defined as a visual condition in which the observer feels either discomfort and/or exhibits lower performance in visual tasks in the presence of an extraneous light source. Glare that is uncomfortable but does not cause significant visual degradation is termed discomfort glare, whereas glare that causes a reduction in contrast due to intraocular light scatter (degradation of the visual image due to stray light within the eye) is termed disability glare (NHTSA, 2007). Although nearly all studies agree that glare from headlights results in discomfort glare for many drivers, a mounting body of research 
suggests that glare levels from modern day headlights is great enough to cause disability glare (e.g., Gray \& Regan, 2007; Theeuwes et. al., 2002; Wood et. al., 2005).

\section{History}

Headlight glare from oncoming vehicles has been a topic of concern among the general public throughout the evolution of the automobile. As improved bulb designs and optics allowed progressively brighter headlights to better illuminate the road ahead, the unintended consequence of oncoming headlight glare continued to increase. With the multiplicative increase in automobile production in the mid $20^{\text {th }}$ century came attempts at reducing the effect of oncoming headlight glare, which was thought to be at the very least a nuisance for many drivers and potentially a safety concern (see Figure 1).

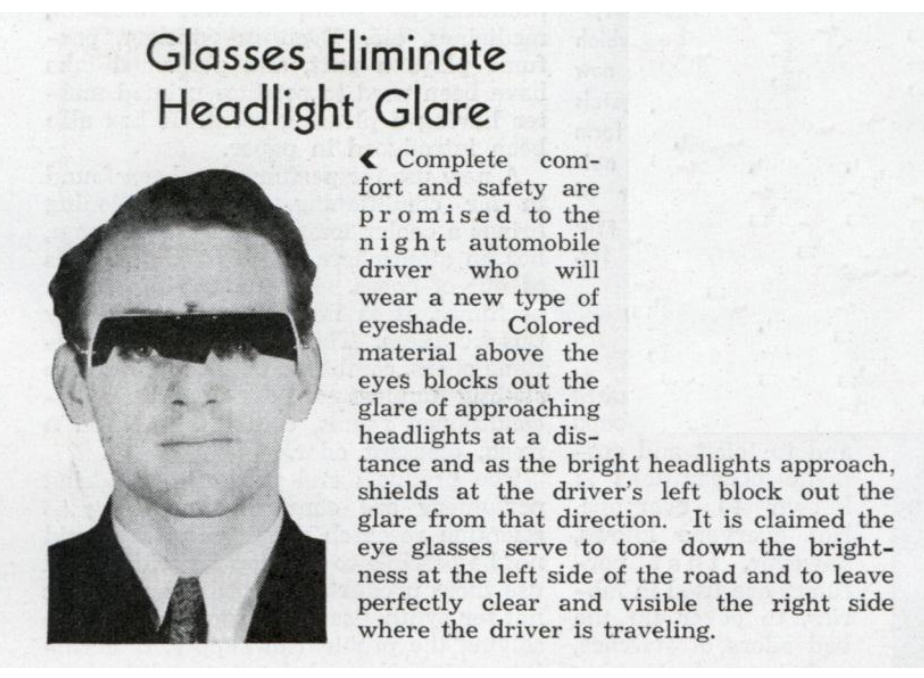

Figure 1. Glasses Eliminate Headlight Glare (Feb, 1938). Retrieved from http://blog.modernmechanix.com/glasses-eliminate-headlight-glare/

With the exception of the current self-tinting rear view mirrors, none of the systems or products meant to reduce glare survived or were effective. This may have been due to the fact that they were cumbersome, unfashionable, costly, unsafe, or simply 
did not work as advertised. Previous attempts included wild ideas such as cut out glasses (as seen in Figure 1), pinhole glasses (which would completely cover the drivers eyes aside from a small aperture in the center used for viewing), special night-time cut-out flip down visors, headlight slats (which attach over headlights and direct more of the light output toward the ground), and even liquid products touted to reduce glare if applied to your windshield.

Until the late 1970s, headlight technology did not make any momentous changes in light quality or output and were standardized to a few types of interchangeable sealed beam lamps. These headlights yielded a yellower hue with a narrower beam field, and replacement of a burned out lamp necessitated the replacement of the entire glass headlight assembly. In the late 1970s technological advances in halogen lighting technology allowed for the implementation of a new style of headlight, in which a halogen bulb was inserted into a reusable housing (Japuntich, 2001). The new halogen bulbs offered a whiter and slightly brighter light than their previous sealed beam counterparts, but the average vehicle lighting intensity remained relatively consistent with the older technology. In the early 1990s, the glare problem began to intensify as sport utility vehicles (SUVs) gained popularity, raising the average vehicle height and therefore potential to cause glare for oncoming traffic (NHTSA, 2007). In the late 1990s, the next evolution of headlights known as High Intensity Discharge (HID) first began appearing in high-end luxury cars. In subsequent years, these lights gained popularity in the general automotive consumer market, with a steadily increasing prevalence (Department of Transportation, NHTSA, n.d.). 
This relatively new HID lighting system features a bulb with no filament to burn out, extraordinarily long life, one-third less power consumption, two-to-three times the lumen output, and a bluish white hue (Department of Transportation, NHTSA, n.d.). Projectors with glass focal lenses are often employed to further distribute the increased light. Drivers with HIDs fitted to their cars experience a wider and brighter field of vision. The brighter HID lights may actually serve to increase driver safety, as the brighter and wider lighting allows the driver to better see the surrounding scene (Flannagan, Sullivan, \& Schoettle, 2008). Many older drivers report that they find the additional lighting beneficial to night driving because they often struggle with vision at lower lighting levels (Owsley, Stalvey, Wells, Sloane, \& McGwin, 2001). Consumers also tend to prefer the bluish white light emitted from HIDs as compared to the yellower light from halogen style headlights (Bullough et al., 2008).

In general, there are many benefits to the newer headlight technology, such as increased visibility for the driver and decreased power consumption; however, these benefits do come with potential costs. As the lighting output is two-to-three times brighter, intensified glare is experienced by oncoming drivers. Many studies have found alarming results when examining the effect of oncoming glare caused by HID headlights in relation to driver performance, especially in regards to older drivers (Anderson \& Holliday, 1995; Sturgis \& Osgood, 1982; Wood, 2002). These include decreased driver awareness of roadway obstacles, decreased safety margin, and overall decreased visual acuity. Interestingly, despite widespread complaints of increased glare experienced from HID headlights, consumer demand for them is ever increasing (Department of 
Transportation, NHTSA, n.d.; NHTSA, 2007). One cause of this heightened consumer demand for ultra-bright headlights may have a direct relationship to the glare problem itself and associated visual disability. For example, Flannagan et al. (2000) found that the negative effects of glare from oncoming headlights were reduced when the brightness of the participants' own headlights increased. That is, as the brightness of one's own headlights is increased, the relative brightness of oncoming headlights is diminished. This consequently allows the driver to see more of the visual field in the presence of oncoming glare. This reduction in perceived glare would partially explain the desire by consumers to demand brighter headlights on their own new car, while simultaneously complaining about the glare caused by them from oncoming traffic.

HID technology was first introduced exclusively in small numbers on luxury cars in the late 1990s. The typical consumer base for luxury car brands leans more toward older drivers, a demographic that is known to be disproportionately susceptible to glarerelated vision problems (Mainster \& Timberlake, 2003). For drivers of those cars at that time, the lighting advantage generated by HID headlights (over the general population using dimmer halogen lights) may actually have been a great luxury. HID headlights increased comfort and visual acuity since these headlights created a luminance advantage as compared to the average oncoming car, which reduced the glaring effect of oncoming headlights. This visual advantage was, however, short-lived, as demand for this same technology from the general public subsequently skyrocketed and HID lights became more pervasive. Now that the brighter HID headlights are commonplace on today's 
roadways, luxury car manufacturers have developed an even brighter solution to offer a lighting advantage over HID's.

The newest generation of headlights utilize LEDs (light-emitting diodes) for their light source. LED headlights are nearly twice as efficient as HID lighting and have the potential to produce significantly more light output than HID headlights with very little power consumption. This new style of LED lighting will eventually replace both halogen and HID headlights because of the steep efficiency gains over older-style lights. Additionally, consumers will most likely desire the added visibility from LED-based technology in their own cars (Bullough, Fu, \& Van Derlosfske, 2002). Given that glare increases with lighting intensity, we should expect increased levels of glare associated with these new lights and further push-back from the public regarding their use (Rumar, 2000).

Many studies in which the effects of glare on human performance were examined revealed especially startling results in relation to HID headlights as compared to halogen. For instance, Gray et al. (2011) suggested that a reason for increased disturbance caused by HIDs lies not only in the increased intensity of the light, but also in the bluish-white color. The results from their study showed that cataract patients with lenses that filtered out blue light spectra were less susceptible to glare-related effects on the visual field contrast ratio as compared to non-filtering lenses.

Similar findings were suggested by The Society of Automotive Engineers in an article by Bullough and Van Derlosfske (2002) that explored problems related to glare from halogen and HID headlamps. This study showed that although HIDs increase driver 
visibility for the vehicle fitted with them, these headlights can cause serious problems related to glare. Both higher intensity and the bluer color spectrum of light associated with HIDs were mentioned as factors relating to increased glare compared to halogen lights. These authors stated that halogen lights needed to be $25-50 \%$ brighter to elicit the same discomfort ratings associated with HID headlights. Driver preference for headlight color was also investigated. Drivers preferred the bluer-white lighting for their own vehicle but overwhelmingly preferred a yellower color spectrum when exposed to oncoming headlights of the same intensity. These findings demonstrated drivers' concerns with the use of HID headlights on other cars but noted the benefit of these headlights for the driver of the fitted vehicle.

Theeuwes, Alferdinck, and Perel (2002) examined the effects of simulated oncoming headlights mounted to an instrumented vehicle that was driven on public roads. Even at low levels of glare, participants had a significant drop in detecting simulated pedestrians on the side of the road. Furthermore, on winding roads participants slowed their vehicles in an attempt to compensate for decreased visual or cognitive performance in the presence of glare. The participants did not, however, practice this same slowing on straight roads under the same conditions. Whether the participants were willing to take a larger risk on a less risky (straight) road with the same visual impedance, or whether participants attempted to self-regulate speed in the presence of glare, it is evident that the glare did induce driver limitations. Dramatic drops in object detection also occurred with older drivers in particular. 
A road-course study by Wood and Owens (2007) examined the visual abilities of drivers of various age groups during nighttime driving. Headlight intensity was varied for participants, with speed of driving and road sign recognition recorded and analyzed to infer driving safety. As headlight intensity emitted from the subjects' own cars decreased, older drivers had decreased recognition of road signs and attempted to selflimit their speed. In addition, older drivers' perceptual abilities decreased significantly faster than that of younger drivers with dim lights. These findings show that although glare emitted from brighter oncoming lights may affect the driving performance of other drivers on the road there is an extraordinary safety benefit for increased luminosity of headlights fitted to the cars of older drivers. Unfortunately, older drivers benefit most from increased headlight intensity from their own cars, but they are disproportionately affected by increased glare from other cars.

\section{Glare and Age Concerns}

As we age, our susceptibility to disability glare increases as our eyes become slower at fast transitions between light levels (Mainster \& Timberlake, 2003). Moreover, intra-ocular light scatter increases with age, as related defects in the cornea, lens, and vitreous fluid, along with conditions such as cataracts, interfere with light transmission. These defects intercept and scatter light before it reaches the retina causing an overall decreased contrast ratio in the visual image (Franssen, Tabernero, Coppens $\&$ van den Berg, 2007). This is experienced as an overall haze or "veil" of light across the visual field. Along with an increase in veiling glare caused by intra-ocular light scatter, older individuals also tend to disproportionately suffer from increased photo-stress (glare) 
recovery time, decreased low contrast acuity, and an overall decreased visual field (Mainster \& Timberlake, 2003). These effects could increase the risk of accidents due to a driver's inability to see obstacles or hazards in the road, or in the driver's peripheral vision. As the effect of glare degrades the visual image, and recovery time from glare exposure increases, an ever expanding older-driver population warrants an examination into the direct effects of glare on driving performance. This is pertinent because the older driver population according to the U.S. Department of Transportation (2011) has increased by $111 \%$ between 1980 and 2011, and is continuing to rapidly expand. Charman (1997) states that the population of older drivers is forecast to reach 17 million by 2031 .

Similar issues for older adults suffering from various eye conditions were illustrated in an article by Babizhavev, Minasyan, and Richer (2009). It was also suggested that as age increases so does intra-ocular light scatter, which is made worse by a number of eye conditions affecting visual acuity such as cataracts. A substantial portion of the population was stated to currently drive under adverse conditions as a result of glare-related visual deficiencies. Although older drivers already have difficulty driving during low-light conditions without the effect of oncoming headlights, intense glare significantly compounds the problems they face with nighttime visual acuity. Indeed, Anderson and Holliday (1995) found elderly drivers to be especially susceptible to decreased contrast ratio (the difference in lighting level between background levels and the light source in question) caused by oncoming vehicle headlights. An example of this would be driving down a dark highway as high beams 
from an oncoming vehicle appear. Some participants chose to self-limit their nighttime driving because of this limitation caused by glare sensitivity. Although this study predated the ultra-bright light emitted from HID headlights, it was found that even the glare from low-beam halogen headlights could significantly reduce an elderly driver's maximum contrast ratio. High-beam headlights, however, resulted in a further exponential decrease in visual contrast ratio, reducing the visual acuity of elderly drivers even further. The cause of these large visual degradations were due to increased lens opacity (clouding of the lens in elderly driver's eyes) due to age. The effect of this extraordinarily decreased contrast ratio would be similar to the incorrect practice of driving in thick fog with your high beams on, where additional light is scattered through the visual scene making it harder to see. These findings warn of the severity of highintensity light exposure on the visual acuity of older drivers even before the introduction of HID technology.

As mentioned previously, HID headlights emit light two-to-three times brighter than do halogen low-beams, and the light output for HID headlights is significantly greater for high-beams. Participants in the study had substantial difficulties in discriminating the direction of motion of a generously sized, but low-contrast, object in their field of view. The authors suggested that the immense visual losses experienced by elderly drivers with exposure to headlight glare would be made even worse with dirty windshields, glasses, or adverse weather conditions such as rain or fog. To illustrate the effect further, the author suggests imagining trying to drive with petroleum jelly smeared over your eyeglasses. Elderly drivers experience relatively little visual acuity problems 
during the day, but night driving places extraordinary visual demands on these drivers resulting in potentially unsafe performance due to oncoming glare.

Similar results were reported by Pulling and Wolf (1980) who found age-related deficiencies in the presence of glare. These authors found that resistance to headlight glare tended to decrease with age, and concluded that glare-resistance was a combination of physiological glare threshold combined with the participants' subjective tolerance to glare discomfort.

Although they did not study night driving, Gray and Regan (2007) examined disability glare caused by low-sun conditions and found that daytime glare conditions also reduced visual performance due to a decreased contrast ratio. They attributed this to glare-induced low visual acuity, poor road-sign recognition, and impaired visual attention. Significant losses in peripheral field object recognition were found in the glare conditions, suggesting that peripheral vision was of even greater importance than was visual acuity in driving performance. Peripheral vision is a key factor in crash avoidance, and older drivers are already at a disadvantage in terms of peripheral vision before the additional detrimental effects of glare. Indeed, Wood (2002) demonstrated a significant disadvantage in peripheral vision for older drivers, even without the influence of glare. With the addition of glare during a real-world road course, older drivers experienced even greater visual impairment.

In an attempt to find a viable solution to the glare-disability problem, Fekete, SikLanyi, and Schanada (2006) examined different wavelengths (colors) of light in an attempt to find which wavelengths created the least amount of glare sensitivity. Blue- 
white light was found to cause increased discomfort glare as compared to more yellow lights. Similar research by Gray, Perkins, Suryakumar, Neuman, and Maxwell (2011) showed that bluer-white light (such as the wavelengths associated with HID bulbs) actually may cause disability glare. The bluer-white light resulted in both decreased contrast ratio caused by intra-ocular light scatter and increased discomfort as rated by the participants. It seems that the bluer wavelengths of light add to effect of glare from HID headlights.

Wood, Tyrrell and Carberry (2005) examined the limitations of drivers to recognize pedestrians during nighttime driving conditions. They found a litany of factors leading to a decrease in pedestrian recognition. Increased age was a significant factor, as well as intensity of glare from oncoming headlights. The contrast or color of pedestrians' clothing was also a significant factor with darker colors yielding higher miss rates as well. As in other previous research, increased participant-vehicle headlamp luminosity was shown to partially counter these effects with high beam headlights improving pedestrian recognition rates. This study showed that, on average, drivers recognized only $5 \%$ of pedestrians in the most demanding condition, which included a combination of glare, black pedestrian clothing, and low-beam headlight visibility from their own car. What is evident from this study is that increased lighting emitted from the drivers' vehicle improves visibility, whereas increased glare received from oncoming vehicles decreases visibility, with more pronounced effects for older drivers. The findings are consistent with much of the current research in the field, which indicates the conflicting safety benefits and detriments of increasing vehicle headlight levels. 
Although benefits may exist for the driver of a vehicle with intense headlights, an oncoming driver may experience disability glare when exposed to them creating a potential safety concern. A study by Gray and Regan (2007) examined disability glare during daytime driving and concluded that disability glare may constitute a safety concern when driver performance was monitored. They found that oncoming headlight glare led to diminished visual acuity, and increased risky driving maneuvers, such as decreased safety margin when making a turn into oncoming traffic, and increased collisions. This study investigated the correlation between glare and increased probability of accidents, and found that the presence of glare resulted in a significantly reduced safety margin (measured in time-to-collision with oncoming cars) when executing turns across oncoming traffic. They also found that older drivers (45-60 years old) in the glare condition demonstrated a significantly reduced safety margin than the younger drivers (18-29 years old) in the same condition.

Theeuwes et al. (2002) conducted another study that supports the argument that significant detrimental effects to driving performance can be caused by glare. They examined the driving performance of participants on public roads in the presence of simulated glare. The goal of their study was originally to measure the level of discomfort glare that participants experienced, which was previously thought to not affect performance. Surprisingly, these authors found a significant degradation of driving performance in terms of visual accuracy, speed of travel, and other important aspects of driving in addition to ratings of discomfort. They theorized that discomfort associated with glare may actually cause distraction, further exacerbating specific losses from visual 
acuity alone. As glare is proportional to headlamp brightness (Mainster et al., 2003) we would expect significantly increased levels of glare from HID headlights compared to halogen headlights.

Given that glare has previously been established by prior research to degrade driver performance, with negative consequences amplified by driver age and oncoming headlight intensity, the current research focused on measuring driving performance in the presence of simulated oncoming headlight glare. The goal of the current study was to simulate a real-world nighttime driving scenario, while monitoring various aspects of driving performance using a realistic driving simulator. As the literature suggests that important differences exist between HID and halogen lights in relation to oncoming glare, both were tested to determine their effects on driving performance. In addition previous research has demonstrated that age-related visual impairment can be exacerbated by glare, so age differences in performance were also examined. Finally, as much of the previous research has suggested that glare of any type may cause driving performance losses, a novel polarizing filter glare-reduction system was tested to ascertain the benefit of one possible improvement (see Figure 2). 


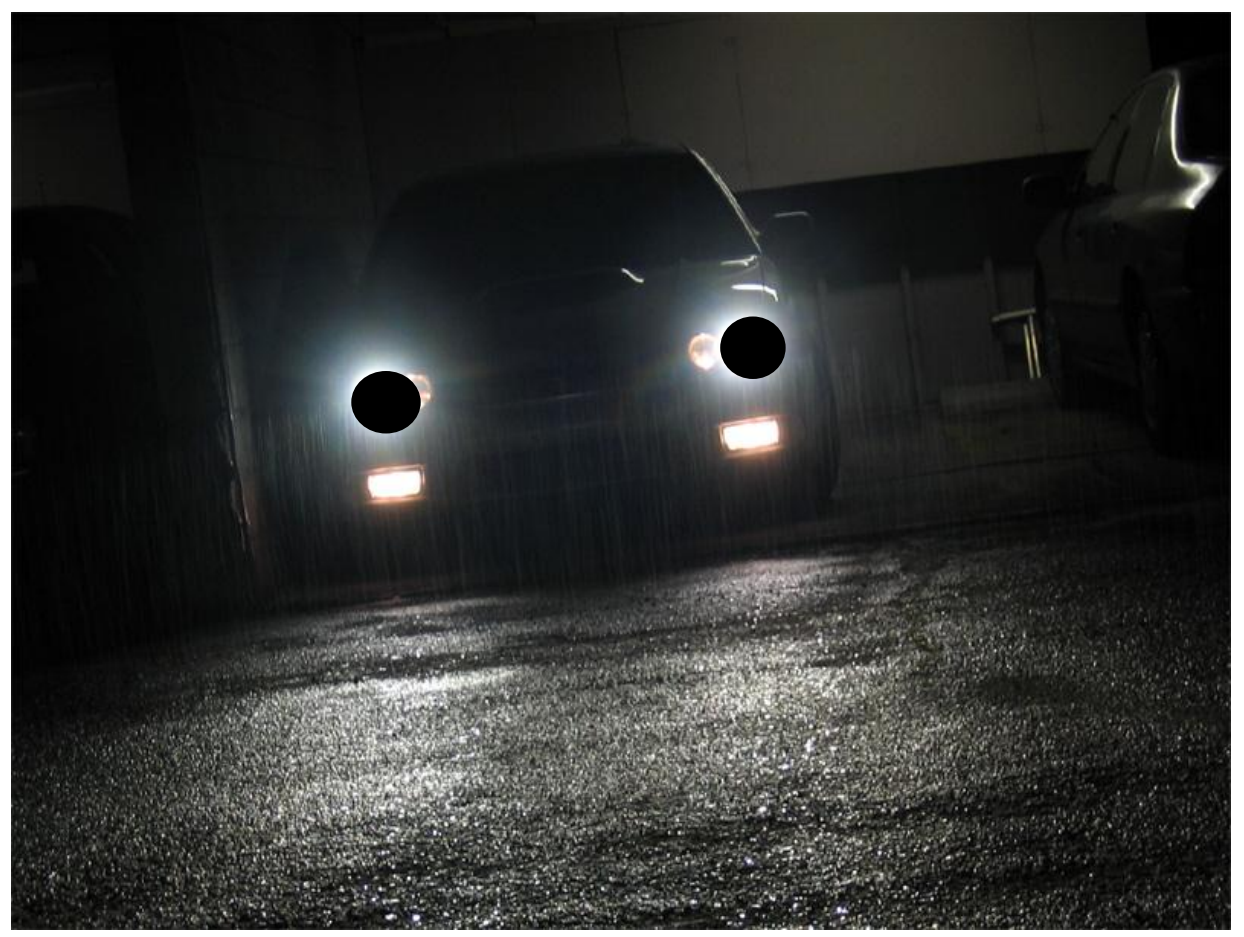

Figure 2. Simulated view of oncoming headlights with a polarized glare-blocking system.

We hypothesized that the glare-reduction system would yield more accurate performance on all measures of driving. In addition, we hypothesized that the use of halogen lights would similarly result in more accurate performance compared to the brighter HID headlights. Finally, we hypothesized that older driver's (age 40+) would experience larger decrements in driving performance due to glare than would younger drivers (18-39). This is because the effect of glare on the visual scene is closely related to a person's susceptibility to intraocular light scatter which increases with age. 


\section{Method}

\section{Participants}

Data were collected from 71 participants of varying ages (18-80) from San José State University and the local community. General Psychology students, campus faculty and staff, as well as local members of the community were recruited via email and word of mouth for participation in this study. Two participants were eliminated from the study because they were not able to complete the experiment due to motion sickness experienced in the driving simulator. Participants were classified in two age groups: younger, aged 18-39 years old $(M=25.2$ years, $S D=5.3$ years, $n=38)$, and older, aged 40-80 years old $(M=60.0$ years, $S D=8.4$ years, $n=33)$.

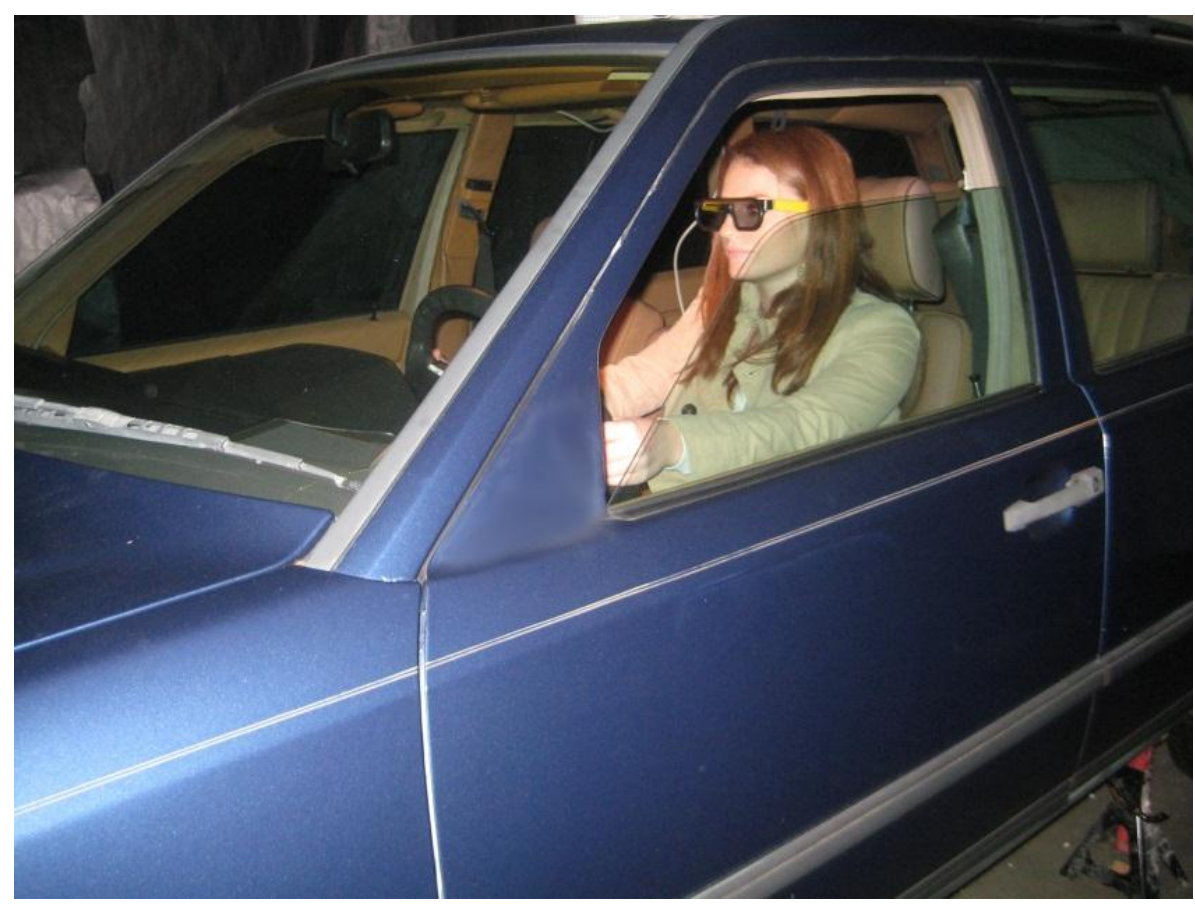

Figure 3. Participant in younger age group sitting in the experimental vehicle. 


\section{Apparatus}

The experiment was conducted in an approximately $60 \mathrm{ft}$ long by $35 \mathrm{ft}$ wide $(18.3$ $\mathrm{m} \times 10.7 \mathrm{~m}$ ) research laboratory typically used by the SJSU Department of Industrial and Systems Engineering. The experimental room was on the first floor which allowed an actual car to be parked inside the laboratory. The room featured a large oval conveyor belt approximately $20 \mathrm{ft}$ long $\times 8 \mathrm{ft}$ wide $(6 \mathrm{~m} \mathrm{x} 2.5 \mathrm{~m})$ in the center of the room. The experimental setup was constructed using a stationary car (a 1989 Mercedes 300TE) that was modified to allow the standard controls inside the car (steering wheel, brake pedal, and horn) to be used as digital input devices for a custom driving simulator running on a laptop outside of the car. This setup gathered simulated driving performance data while provided a realistic driving experience as it allowed participants to adjust the seat position (forward, backward, up, and down) as they would in real-world driving.

Although it was significantly more complex than a simple desktop setup, we reasoned that an optimal view of the virtual "road" and comfortable access to the controls might reduce possible confounds caused by individual ergonomic differences between participants. The use of an actual car in the study also yielded a more realistic experience that more closely mimicked real-world nighttime driving. To further simulate the nightdriving environment, the experimental room was darkened by hanging black curtains from floor to ceiling surrounding the entire experimental area (see Figure 4). The floors were also lined by black curtains to eliminate as much extraneous ambient light as possible. No ceiling lights were used within the experimental area during the experimental sessions. 


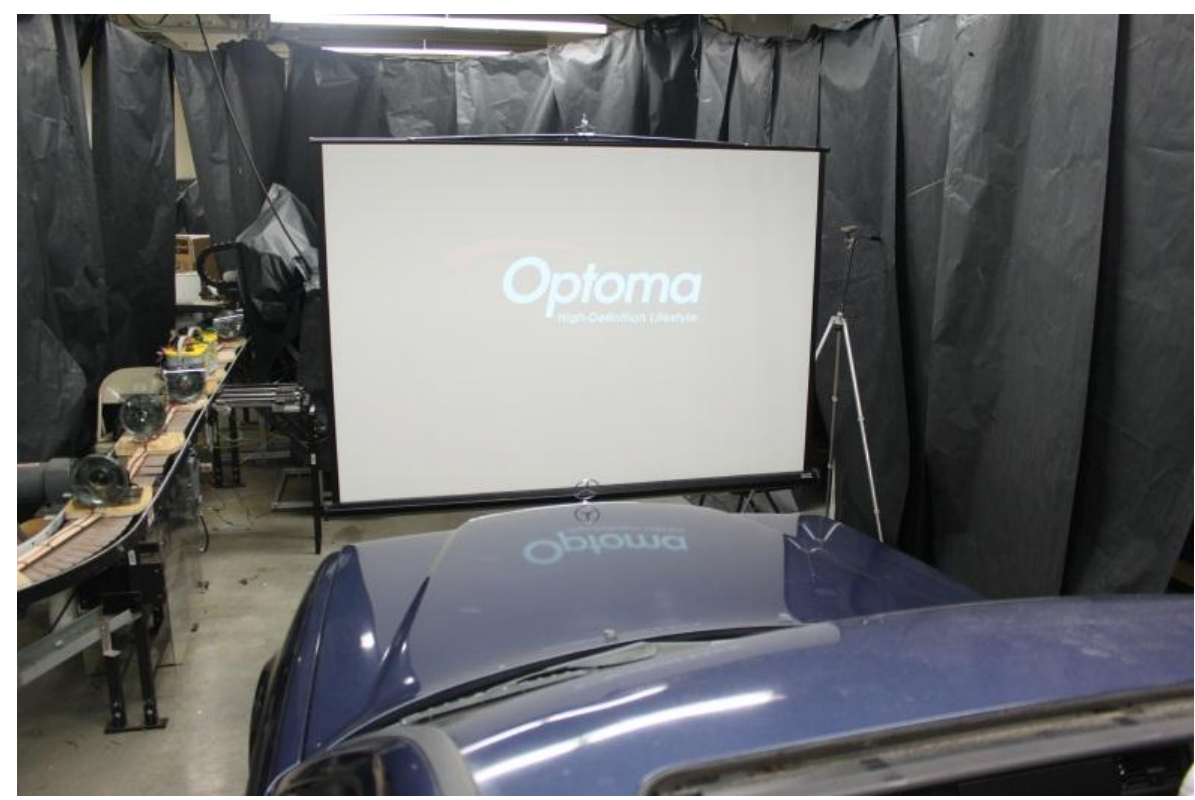

Figure 4. Black paper curtains used to darken experimental area can be seen surrounding the car.

Hardware. The test vehicle was parked in the experimental room and placed on jack-stands to allow the steering wheel to rotate freely. Because the height of the conveyor could not be modified, jack-stands were used to raise the height of the car so that the center of both oncoming and test vehicle headlights were matched at approximately 40 in $(102 \mathrm{~cm})$. 


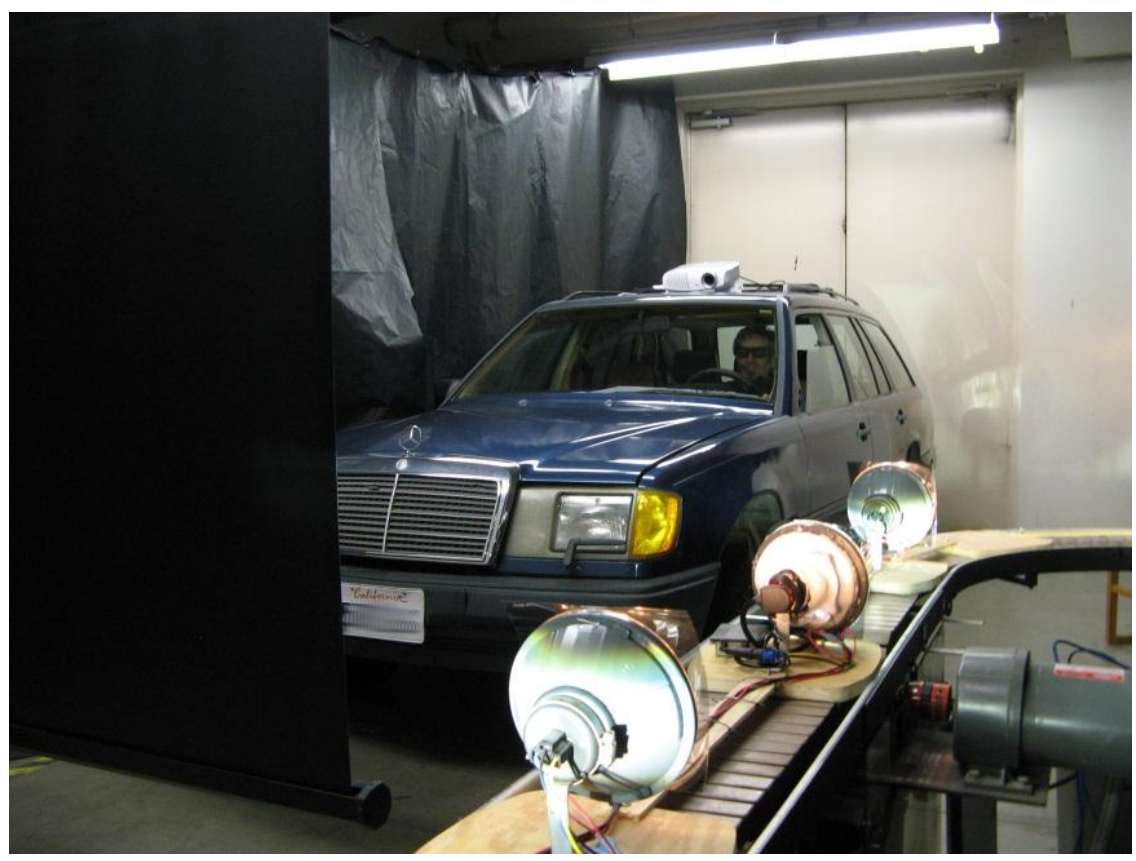

Figure 5. Headlights on moving conveyor belt simulating oncoming traffic.

Directly in front of the car and $2 \mathrm{ft}(61 \mathrm{~cm})$ to the left sat the oval-shaped industrial conveyor system. This conveyor was oriented such that the long stretch of belt sat $2 \mathrm{ft}(61 \mathrm{~cm})$ to the left of the car moved linearly toward the car as the conveyor moved in the counter-clockwise direction. This stretch of conveyor constituted the path of a virtual "oncoming car." To improve the illusion of "headlights from an oncoming car," the loop of the conveyor was divided with black curtains so that the return portion was obscured from view. This left visible only the $20 \mathrm{ft}(6 \mathrm{~m})$ long linear portion that approached the vehicle. For ease of control by the experimental operator, the conveyor was modified to be operated wirelessly by remote. The conveyor speed was measured at approximately $0.5 \mathrm{ft} / \mathrm{s}(0.15 \mathrm{~m} / \mathrm{s})$ or $0.34 \mathrm{mph}(0.55 \mathrm{kph})$.

Arranged on top of the moving conveyor platform were four equally spaced $12 \mathrm{~V}$ deep cycle automotive batteries, used to power 16 individual headlights of two types ( 8 - 
$35 \mathrm{w}$ projector HID, 8 - 55w halogen $\mathrm{H} 4$ reflector). The headlights were arranged single file on the conveyor in a staggered manner, alternating between HID and halogen around the conveyor loop. Both the halogen and HID headlights were DOT approved and resided in similar 7 in. round housings. A wireless control relay was added between the battery and the lights, so that groupings of lights (all halogen, or all HID) could be remotely activated by the experimental operator depending on participant condition. Each headlight was spaced 18 in. apart on the conveyor belt, and a maximum of four active headlights of the same grouping could be seen on the $20 \mathrm{ft}$ visible stretch at any one time.

Sheets of transparent linear polarizer (43\% light transmittance uncrossed, .05\% light transmittance crossed) covered the face of each headlight. Two specialized sets of eyeglasses were also constructed using the same polarizing sheet to replace the lenses of the eyeglasses. These identical eyeglasses were marked with either blue or yellow labels corresponding to the degree of rotation ( 0 or 90 degrees) of the polarizing lens contained in the glasses. As the polarizing film in front of the headlights limited the light transmittance to vertical wavelengths only, the glasses would either pass or block light depending on the rotation of the polarizing lens in the glasses. 


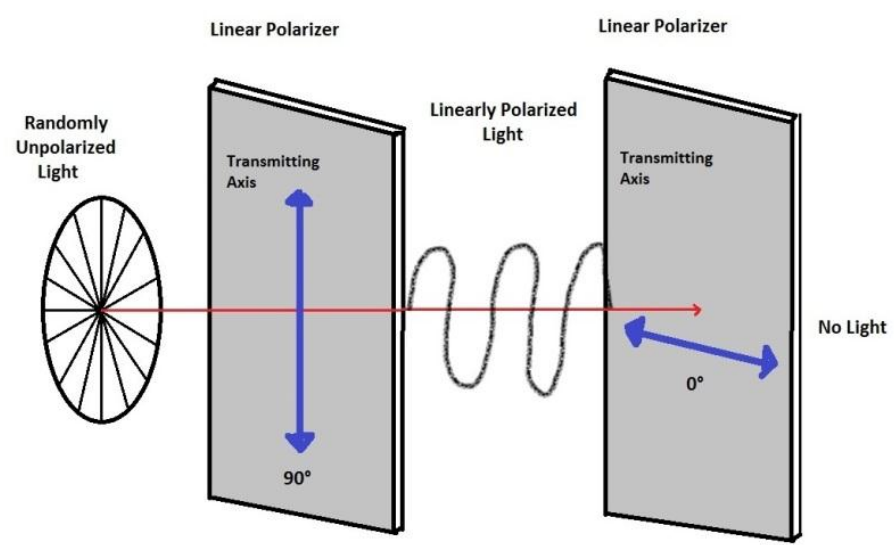

Figure 6. Effect of opposed polarized filters on light transmittance.

The blue glasses blocked almost all light (.05\% light transmittance) from the eyes of the participant, while the yellow glasses (43\% light transmittance) allowed light from the headlights to pass through. The glasses could be fitted over top of existing glasses, allowing participants to use their standard eyewear (if needed) during the experiment. The glasses did not interact with anything aside from the headlights in the visual field and caused only a slight overall dimming of the environment in general.
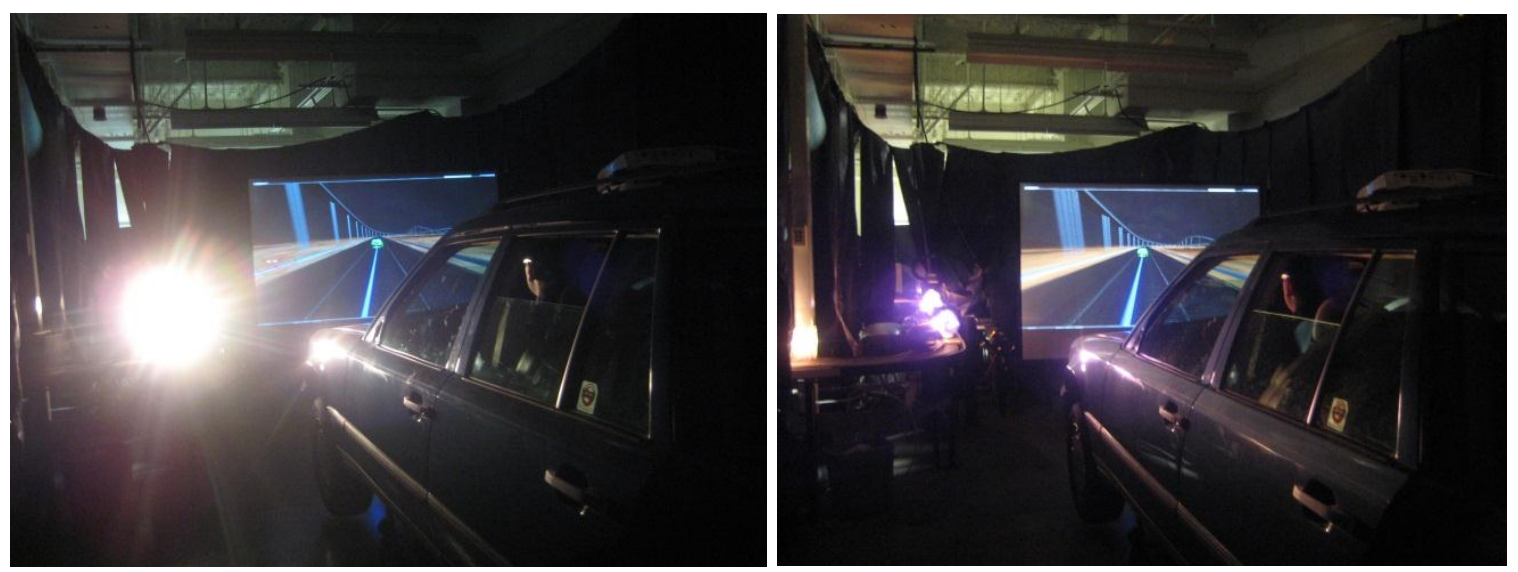

Figure 7. Comparison of light transmittance through in-phase (left) and out-of-phase (right) polarizing filter over camera lens. 
A projector $(5 \mathrm{ft}$ wide $\mathrm{x} 4 \mathrm{ft}$ tall) screen stood $4 \mathrm{ft}$ in front of the test vehicle. A high definition projector (Optoma model HD180, USA) mounted on the roof rack of the test vehicle projected the interactive driving simulator. This placed the participant approximately $8 \mathrm{ft}$ from the screen. The aspect ratio and resolution used for this display was 1920x1080. A laptop computer (Sony Vaio model VPCZ1, running Windows 7) running a custom driving-simulator was situated in the trunk of the car. The laptop ran the simulator, output a visual signal to the projector, and received wireless USB inputs for the steering wheel movement, horn actuation, and brake pedal actuation.

Steering wheel rotational data was collected by placing a gyroscopic-type mouse (Gyration model AS04024, USA) placed inside a custom module, which replaced the airbag in the center of the steering wheel. This module was constructed in two parts, an outer plastic shell that was vacuum-formed to the shape of the original airbag (then coated in black vinyl paint), and an inner structure that held the gyroscopic wireless mouse in the vertical orientation.
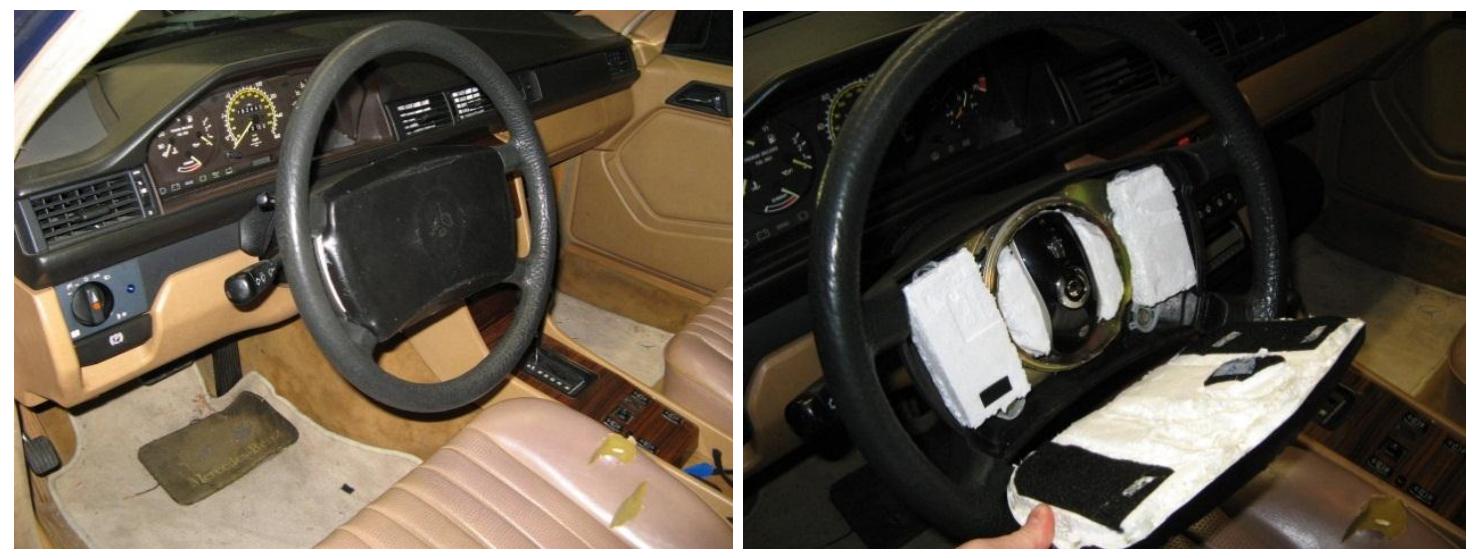

Figure 8. Installation of gyroscopic mouse into faux-airbag. 
The driving simulator mapped the vertical rotation of the mouse (caused by turning the steering wheel) to the rotational angle of the virtual wheel in the driving simulator. As the wheels of the vehicle were lifted off of the ground the steering wheel was allowed to rotate freely, although a small amount of internal resistance from the steering rack added to the feel of driving a real car on a road, though still less than is found on a moving vehicle with positive steering feedback. The wireless mouse placement inside of the center of the steering wheel also doubled as a wireless output device to capture presses of the horn (see Figure 8). The simulator software was programmed to map the left mouse button click to the horn, and a small actuator was placed inside of the faux-airbag shell to click the left mouse button when the center of the airbag was pressed. Lastly, to capture brake pedal presses, a second wireless mouse was placed under the brake pedal with an actuator arm attached to the brake pedal. The actuator arm pressed the right button on the wireless mouse, sending a right mouse-click signal to the computer. The right mouse-click signal was mapped to the virtual brake pedal in the driving simulator software.

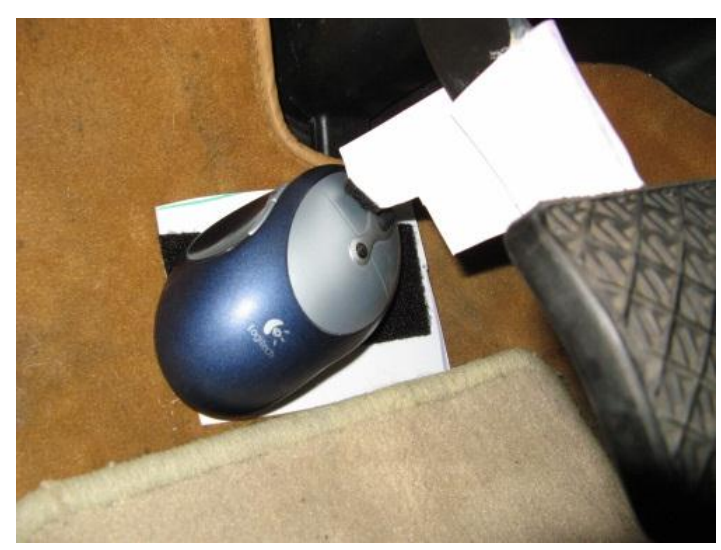

Figure 9. Wireless mouse placed under brake pedal, with actuator arm attached to pedal. 
Software. As stated above, a custom driving simulator was created for this experiment. Realistic physics were employed to give the virtual car life-like behaviors and reactions to steering and braking. The simulator featured a one-way, three-lane highway, with guardrails on either side of the road. The surrounding scenery was darkened to give the appearance of driving at night, or low lighting conditions so as not to adversely affect the visual perception of the participant with brightly lit features (see Figure 10).

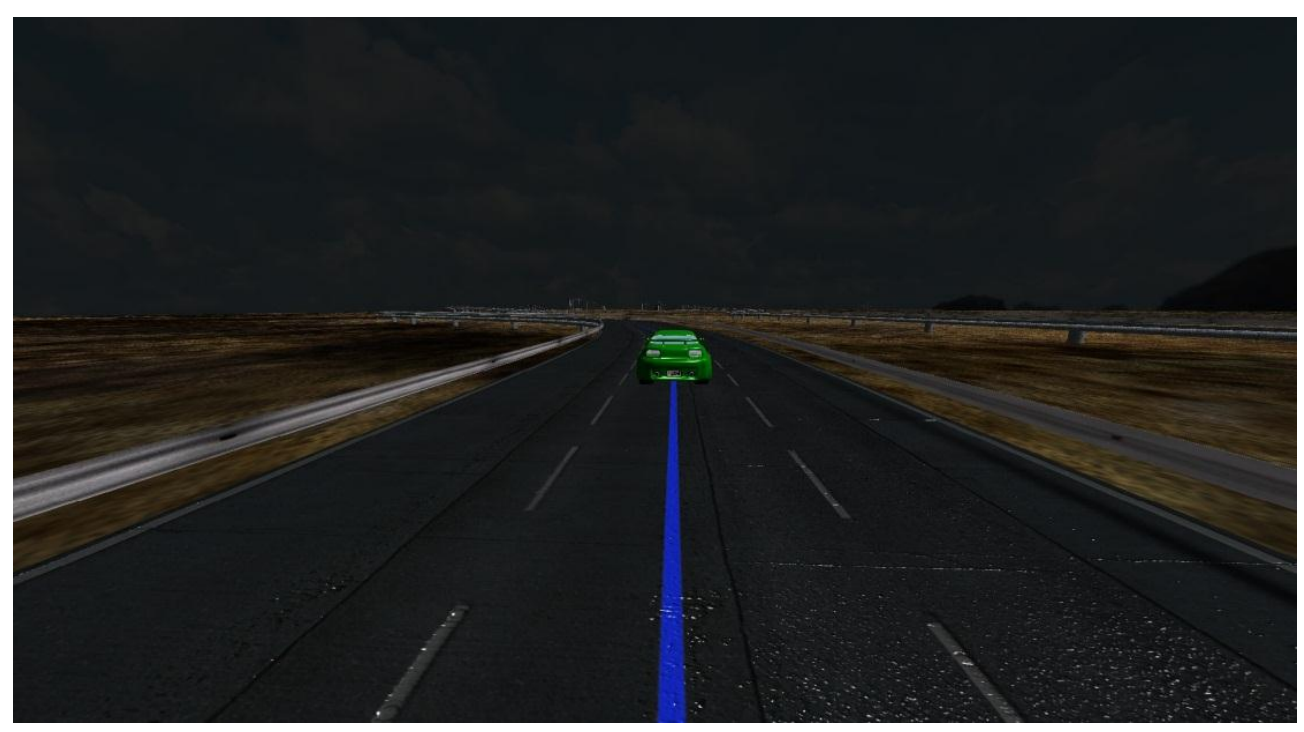

Figure 10. Screenshot of roadway produced by the simulator software.

The simulator was set in the first-person viewpoint so that what was displayed on the screen was roughly the view through a windshield of a car driving down the virtual road. 


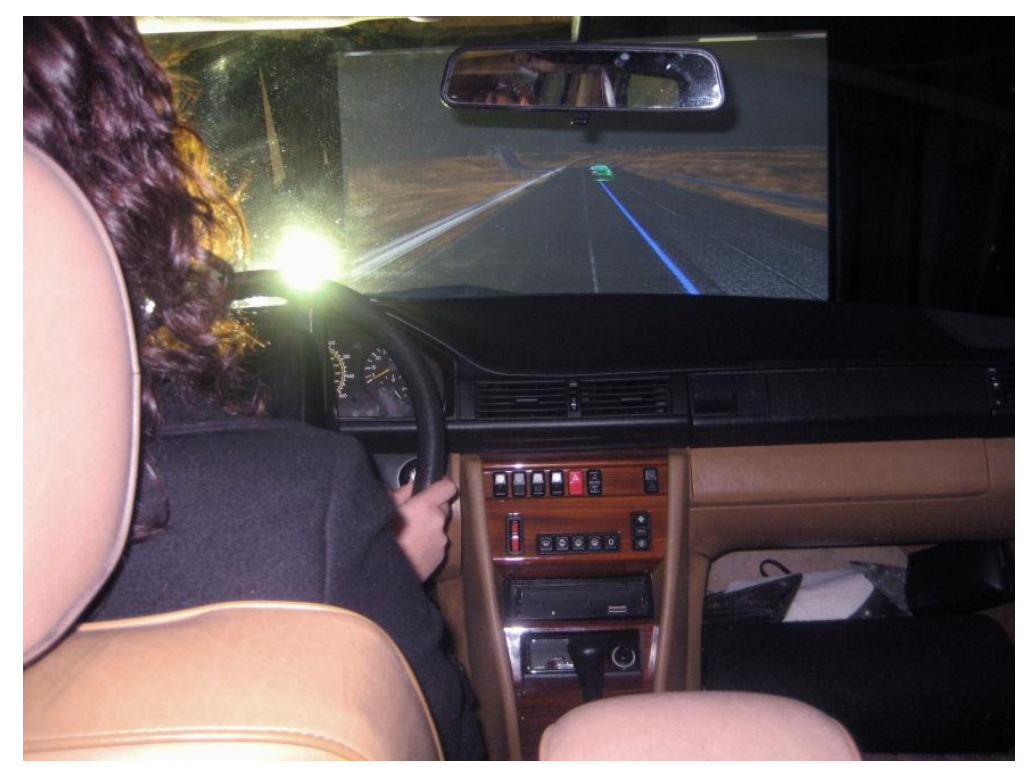

Figure 11. View of driving simulator from inside test vehicle.

The track was designed in two sections, with the first piece consisting of mainly curves and the second section consisting of mainly straight sections of road. The curved section took approximately $1 \mathrm{~min} 24 \mathrm{sec}$ to navigate, while the second straight section took approximately $2 \mathrm{~min}$ to navigate for a total of $3 \mathrm{~min} 24 \mathrm{sec}$ per condition. The first half of the track was curved with six 90-degree tighter corners, and the second half of the track was relatively straight with two long and sweeping 15-degree curves. The virtual vehicle speed was set to $60 \mathrm{mph}$ equivalent in the simulator and was not alterable by the participant.

Three simultaneous tasks (steering, braking, and honking the horn) were required of the participants in each trial. The data gathered from these tasks created the basis for deriving 'driver-performance' averages for each condition. The tasks were identical in each condition aside from interval (brake and horn presses) and location (horn presses), which were both randomized. The steering task consisted of a blue line, which ran down 
the middle of the center lane for the length of the course. This line represented the ideal steering path, which equated to a score of ' 0 ' if the virtual car perfectly followed this path. Guardrails lined the outermost boundaries of lanes one and three, and equated to a +100 or -100 score, respectively. The software recorded a value for instantaneous position once every $500 \mathrm{~ms}$. At the end of the trial, the software calculated the absolute values of these scores to map of total instantaneous deviation every $500 \mathrm{~ms}$. The software then calculated an average deviation across all of these values. Both the curved and straight sections of the course were combined in this process to derive a single deviation score for the trial. These average deviation from ' 0 ' was used to compare 'steering performance' (SP) between trials.

The braking task was achieved by using a green colored lead car that was always present in the center lane, roughly 3 to 4 car lengths ahead. This car followed the 'ideal path' in the center lane and always remained approximately the same distance ahead of the participant's car. The green lead car spontaneously turned from green to red accompanied by the border of the screen flashing red. At this point an internal time counter in the simulator would initiate. As soon as the participant pressed the brake pedal, the lead car returned to the original green state and the counter stopped. This method was used to capture 'time to brake' (TTB) data for the participants. A randomizer function was used to initiate the TTB event so that it could not be predicted by the participant. Six TTB events occurred per trial.

A final task, honking the horn, was used to gather 'visual awareness' (VA) data from the participants. A large cartoon squirrel was programmed to appear in one of nine 
virtual quadrants on the screen ( $3 \times 3$ matrix) as depicted in Figure 12. Participants were instructed to press the center of the steering wheel to 'honk the horn' if they saw the squirrel appear in any location on the screen (although no audio output was produced by this action). The image faded in over a 500-ms interval and disappeared after participant input or the maximum time (approximately $14 \mathrm{~s}$ ) elapsed, whichever came first. A randomizer function was used to initiate the VA event so that location and interval could not be predicted by the participant. Nine VA events (one in each of the nine quadrants) occurred per trial (see Figure 12). Although the TTB and VA tasks were somewhat similar, each was unique and measured separate aspects of driver proficiency. The TTB event measured braking time in relation to a visual event in the center of the screen, while the VA event measured novel object recognition abilities in non-predictable locations. As both TTB and VA event timing was randomized, it was possible for both events to potentially occur simultaneously.

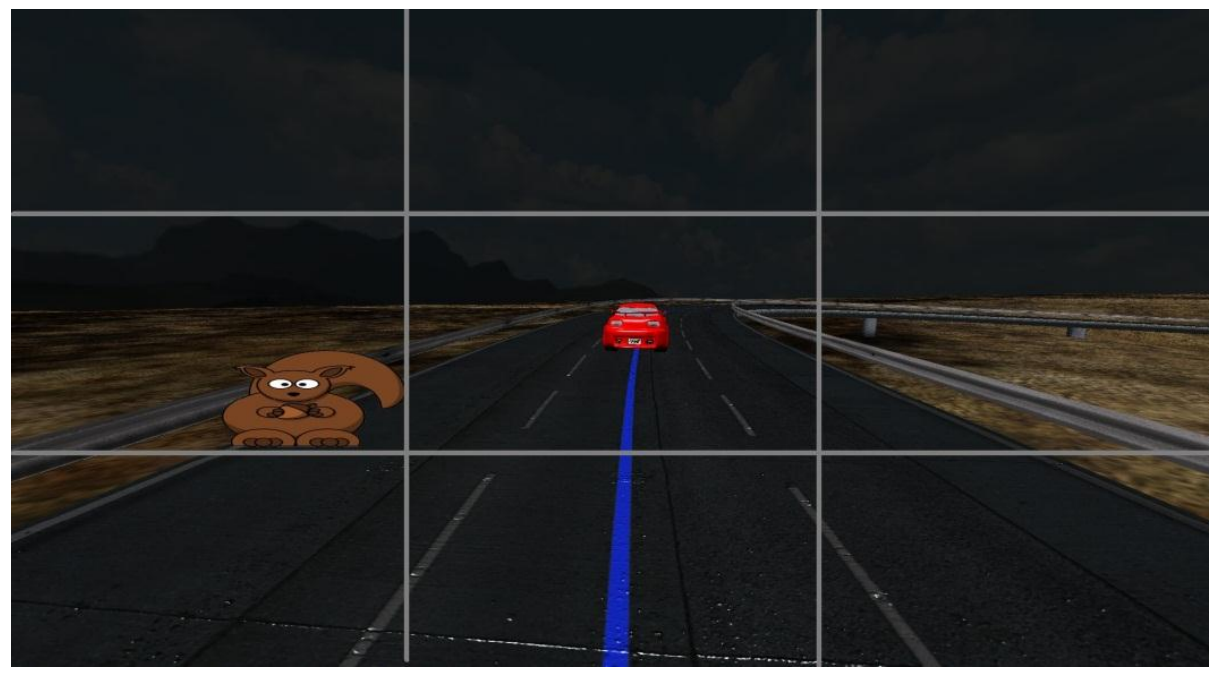

Figure 12. Screenshot of visual awareness (VA) task with artificial overlay grid illustrating the $3 \times 3$ matrix of quadrant locations. 


\section{Procedure}

Before participation in the study, subjects received a brief overview regarding what they would experience, gave their consent to participate (see Appendix A), and completed a demographic survey (see Appendix B). In the initial demographic survey, participants were screened to verify that they held a current driver's license. The intake survey also asked participants for their age, gender, and to describe any known eye conditions they had. If the participants reported wearing eyeglasses during typical night driving, they were asked to wear the same eyewear for the duration of the experiment. It took around 5 min to process each participant; this gave some time for their eyes to adjust to a lower light level. As a result, the lighting in the waiting area was kept to a minimum and ambient light from outside sources was blocked out.

The participants were then led through a curtain into the darkened testing area, and asked to enter the vehicle. Participants were then shown the seat adjustment switch and asked to make adjustments so that they could comfortably reach the brake and steering wheel, as well as have an unobstructed view of the road. After getting situated, the participants received standardized instructions for the experiment based on a preformatted script (see Appendix B). An explanation of the tasks required in the simulator "steering, honking, and braking" were then explained. For the "steering" task, participants were asked to do their best to stay within the center of the three lanes of travel, with the blue line in the center lane representing a visual reminder of their intended path. For the "braking" task, participants were reminded that their virtual vehicle was following behind the car pictured in the simulator. It was explained that this 
car would turn from green to red at any moment to signify braking, and that the participant should depress the brake pedal in the vehicle as rapidly as they could, which would immediately cause the car ahead to return to the green color. Next, for the "honking" task, it was explained to the participants that a large brown cartoon squirrel will randomly appear on the screen, and will remain there for approximately $15 \mathrm{sec}$. The participant was instructed to press the center of the steering wheel, as if honking the horn, at which point the squirrel will disappear. Finally, it was explained to the participants that the initial trials of the simulator would not be recorded and were solely for training to practice the three required tasks. Participants were asked to complete as many practice trials as needed until they felt proficient enough to perform the tasks required, at which point they would verbally verify that they felt ready to proceed.

Participants completed a practice trial of the simulator course, which lasted a minimum of $3 \mathrm{~min} 40 \mathrm{sec}$, and longer for participants that required more practice. After participants stated that they felt ready to begin, they were shown the two types of glasses (blue and yellow) and instructed to put on one of the two types depending on the test condition. At this point the experimental trials began. 


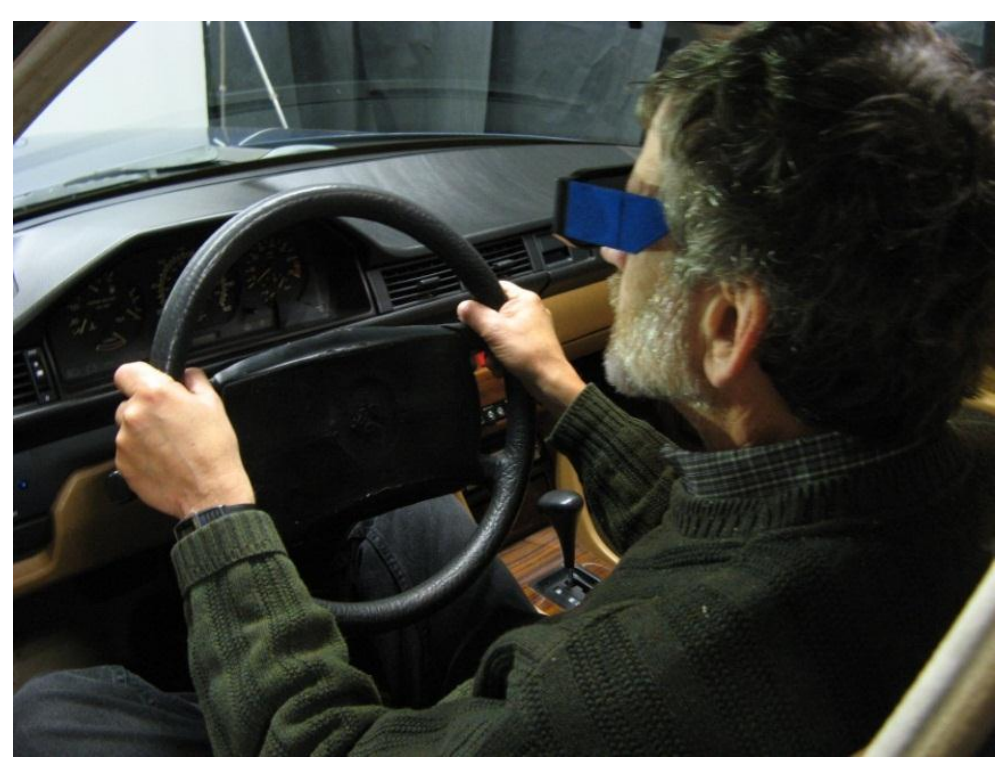

Figure 13. Participant wearing blue glare-blocking type glasses.

All participants experienced four experimental conditions and a minimum of one practice trial, with the course layout identical for every trial. In an attempt to counteract any learning effects for track path and required tasks, all experimental condition ordering was randomized between participants. At the conclusion of the experiment, participants were asked to complete a short post-experiment survey regarding their experiences in the simulator.

\section{Dependent Variables and Data Analysis}

Five measures were analyzed, including steering performance (SP), time-to-brake (TTB), time-to-brake - false positives (TTB-FP), visual awareness (VA), and visual awareness - false positives (VA-FP). SP was defined as the average steering deviation from the intended path of the virtual vehicle (the center of the middle lane), with an increase in average score associated with less accurate steering performance. TTB was defined as the average amount of elapsed time between the lead car turning red and the 
participant pressing the brake pedal, with an increased average TTB value associated with increased delay in response to the braking event. Erroneous brake pedal presses (false positives) during the TTB task were recorded as TTB-FP. These 'errors' or false positives were defined as a participant pressing the brake pedal when no input was required (the lead car remained green in color). The analysis was performed on the total number of TTB-FP occurrences per trial, with increased values associated with more erroneous responses. A metric for VA was created by taking the total number of missed visual events (large cartoon squirrel appearing on the screen with no participant response) per trial. An increased VA measure was associated with decreased visual object recognition ability. Erroneous horn presses during the VA task were recorded as VA-FP and subsequently analyzed. These 'errors' were defined as a participant pressing the horn when no input was required (no visual stimulus appeared on the screen). Increased values for VA-FP were associated with increased instances of erroneous presses.

Data were analyzed using $2 \times 2 \times 2$ repeated measures factorial ANOVA. Data were $\log$ transformed (base 10) to meet the homogeneity of variance and normality assumptions prior to the statistical analysis. Type of Glasses (glare-blocking vs. nonglare-blocking) and Headlight Type (halogen vs. HID) served as within-subjects factors and age (under forty vs. forty and over) served as a between-subjects factor. For all analyses, $\alpha$ was set to .05. Untransformed means, standard deviations, and sample sizes appear in Table 1. Similarly, all figures displaying results present untransformed data. Sample size differs throughout conditions as a result of a small percentage of missing data output files. 


\section{Results}

\section{Steering Performance (SP)}

We found no significant difference in SP for headlight (HID or halogen) type $[F(1,57)=0.98, p=.326]$. No significant SP difference was found using the head mounted glare-blocking system $[F(1,57)=1.46, p=.233]$. The analysis did, however, yield a significant age difference on the SP task $[F(1,57)=14.75, p<.001]$ with younger drivers performing better than the older drivers, with overall reduced steering deviation scores (see Figure 14).

\section{Steering}

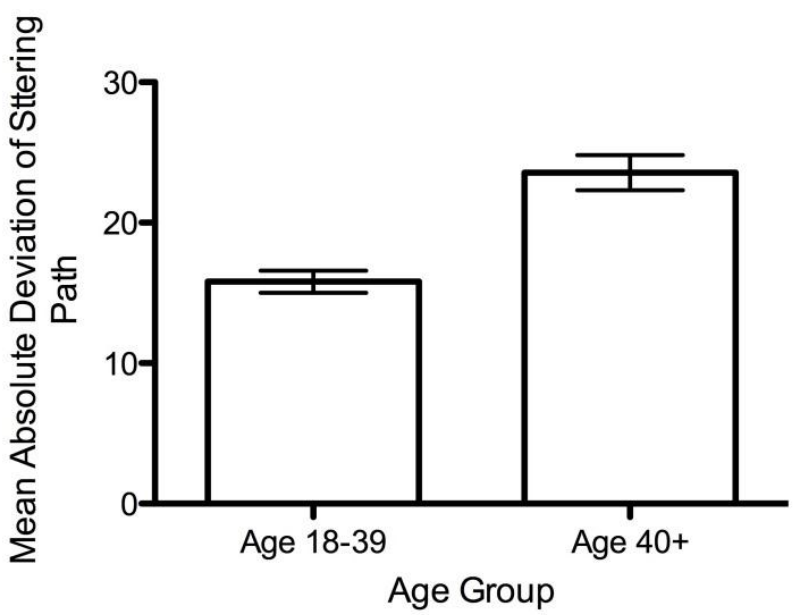

Figure 14. Age differences in performance on steering task.

No significant two-way interactions were found between age and headlight type $[F(1,57)=1.93, p=.171]$, age and headlight blocking system $[F(1,57)=3.34, p=.073]$, or type of lights and headlight-blocking system $[F(1,57)=0.45, p=.505]$. The threeway interaction between age, headlight type, and headlight blocking system also was not significant $[F(1,57)=0.01, p=.921]$. In summary, mean steering performance differed 
only for age. Overall the older drivers performed significantly worse on the steering task than the younger age group, regardless of other conditions.

\section{Time-to-Brake (TTB)}

We found no significant difference for TTB based on type of headlights $[F(1,60)$ $=1.70, p=.197]$, as well as use of the glare-blocking system $[F(1,60)=3.50, p=.066]$. The analysis yielded no difference in time to brake performance between the two age groups $[F(1,60)=2.20, p=.143]$. No significant two-way interactions were found between type of headlights and age $[F(1,60)=0.02, p=.889]$, type of headlights and glare-blocking system $[F(1,60)=0.06, p=.810]$, or age and glare-blocking system $[F(1$, $60)=0.15, p=.700]$. The three-way interaction between age, headlight type, and glareblocking system also did not yield significance $[F(1,60)=0.68, p=.412]$. In summary, time-to-brake was not affected by type of headlight or use of the head mounted glareblocking system. In addition, age differences between participants did not significantly affect the average TTB response.

\section{Time-to-Brake - False Positive (TTB-FP)}

We found a significant difference in TTB-FP pedal presses for headlight type $[F(1,60)=4.20, p=.045]$, with the halogen lamps leading to increased false positives over HID lamps. No significant difference in TTB-FP rates were found when utilizing the head-mounted glare-blocking system $[F(1,60)=0.03, p=.863]$. Age was found to be a significant factor influencing TTB-FP responses $[F(1,60)=7.59, p=.008]$, with drivers over 40 making more erroneous pedal presses than their younger counterparts (see Figure 15). 
Time to Brake

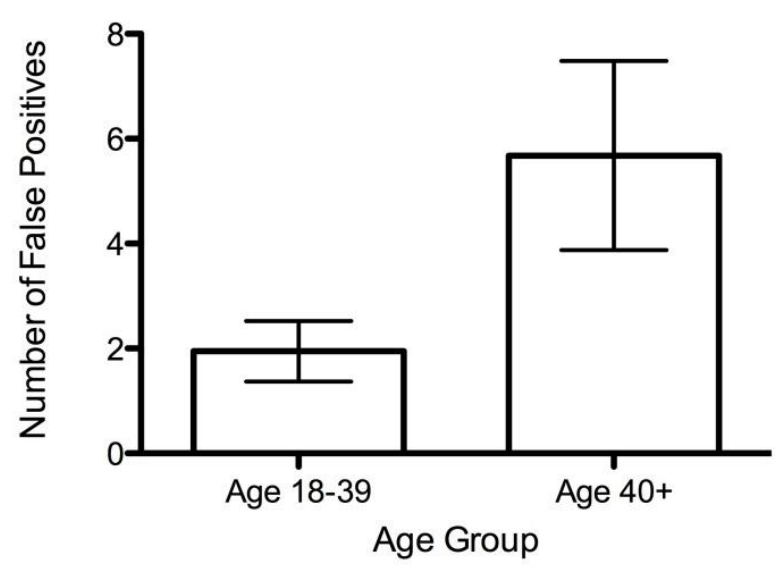

Figure 15. Age differences in false-positive responses during braking task.

No significant two-way interactions were found for TTB-FP events between type of headlights and age $[F(1,60)=1.48, p=.229]$, type of headlights and glare-blocking $[F(1,60)=0.49, p=.488]$, or age and glare-blocking $[F(1,60)=0.03, p=.873]$

Similarly, the three-way interaction between age, headlight type, and glare-blocking did not yield significance $[F(1,60)=3.17, p=.080]$. To summarize, older participants were found to make significantly more overall erroneous brake pedal presses than the younger participants. Type of headlight was also found to be a significant factor in affecting erroneous brake pedal presses, with halogen lights yielding a significant increase in erroneous responses as compared to HID headlights.

\section{Visual Awareness (VA)}

We found a significant effect of headlight type on visual awareness, with the HID headlights leading to increased miss-rates as compared to the halogen headlights $[F(1$, 69) $=12.94, p=.001]($ see Figure 16). 


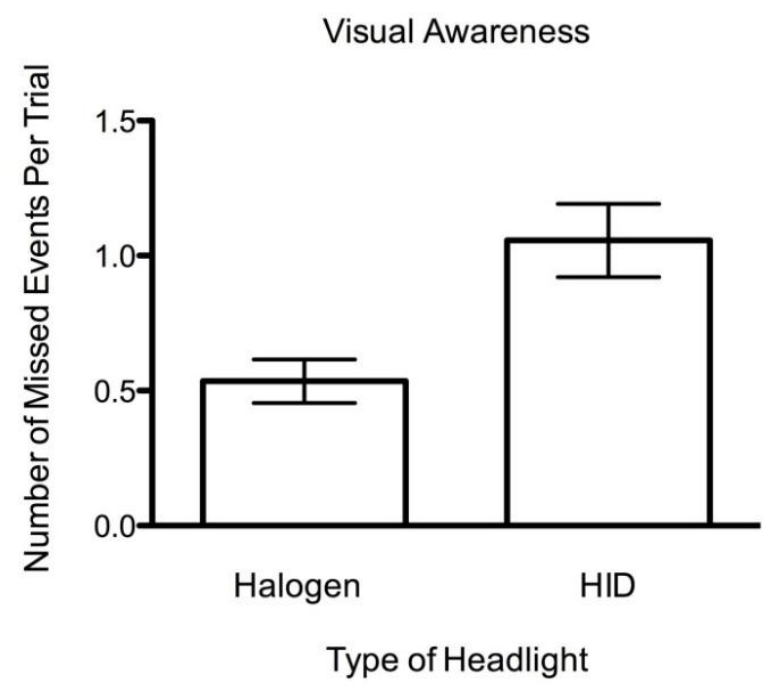

Figure 16. Performance differences with varied headlight type during visual awareness task.

In addition, the non-glare-blocking system yielded increased miss rates as compared to the glare-blocking system $[F(1,69)=37.03, p<.001]$ (see Figure 17).

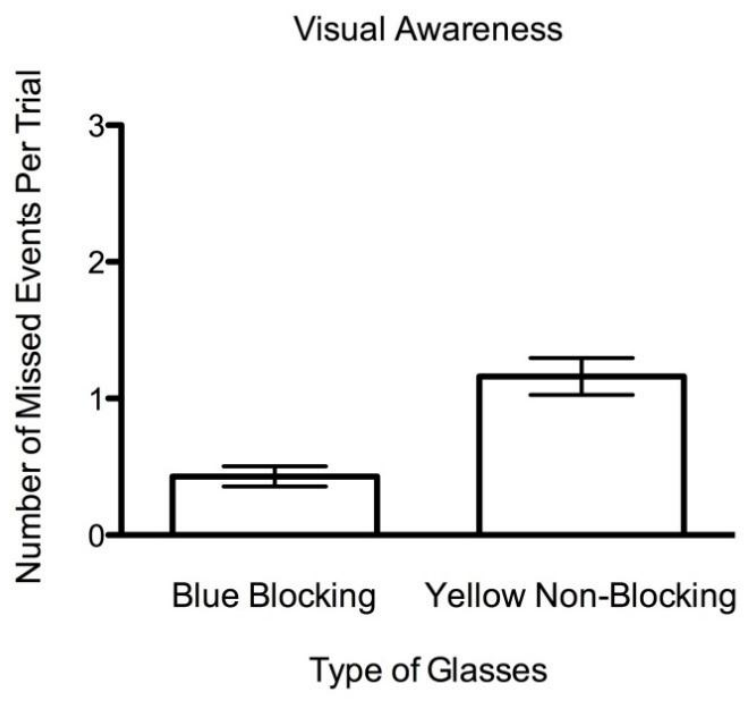

Figure 17. Performance differences with use of headlight-blocking system during the visual awareness task. 
Age was also a significant factor regarding VA performance, with the analysis suggesting that older drivers missed more visual events than their younger counterparts $[F(1,69)=10.94, p=.001]($ see Figure 18).

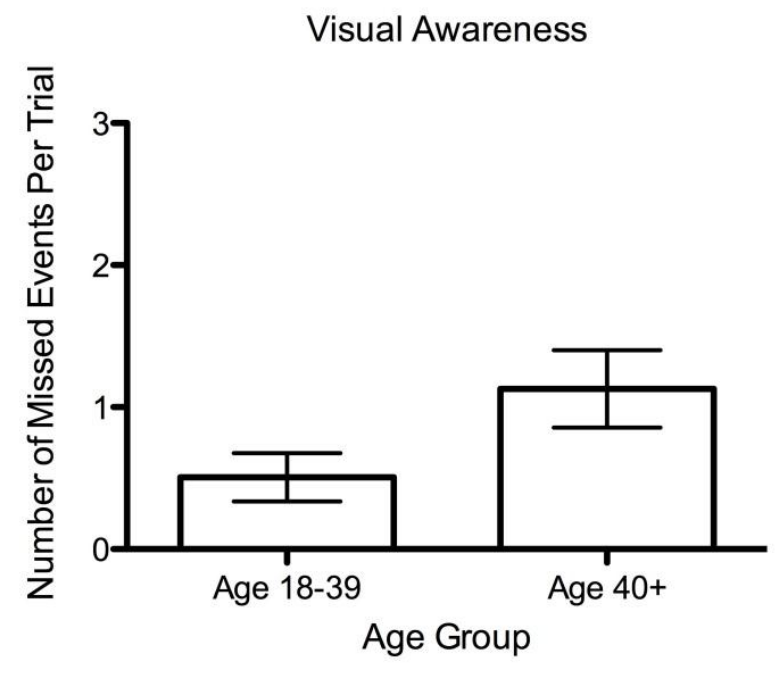

Figure 18. Performance differences in age group during the visual awareness task.

A two-way interaction between glare-blocking system usage and age was found to be significant $[F(1,69)=4.75, p=.033]$. The visual awareness miss rates of younger adults improved when using the glare-blocking system, but this effect was significantly more pronounced for older adults. In other words, older adults appeared to be significantly more affected by glare than younger adults, though both groups saw substantial performance losses in the high-glare condition (see Figure 19). 


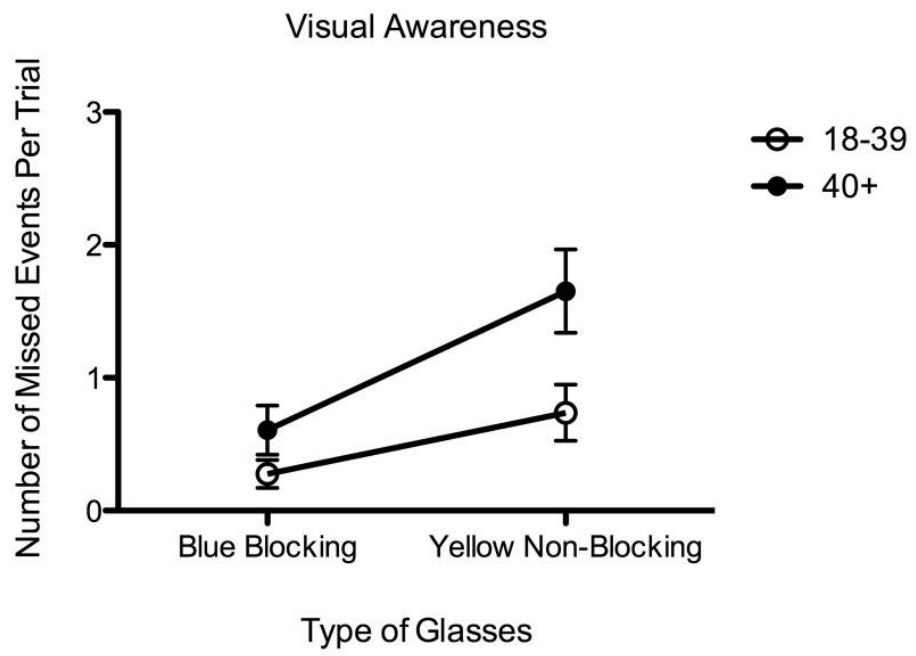

Figure 19. Two-way interaction between age and use of headlight-blocking system during visual awareness task.

A second two-way interaction between glare-blocking and headlight type was found to be significant, as well $[F(1,69)=12.25, p=.001]$. Data from this two-way interaction suggests that although there was an increased VA miss rate for HID lights (vs. halogen) that the magnitude of this effect was increased during the high-glare condition. Stated another way, the participants had fewer misses across the board when using the glare-blocking system, but performance gains were amplified when this system was used in conjunction with the high-glare oncoming HID headlights (see Figure 20). 


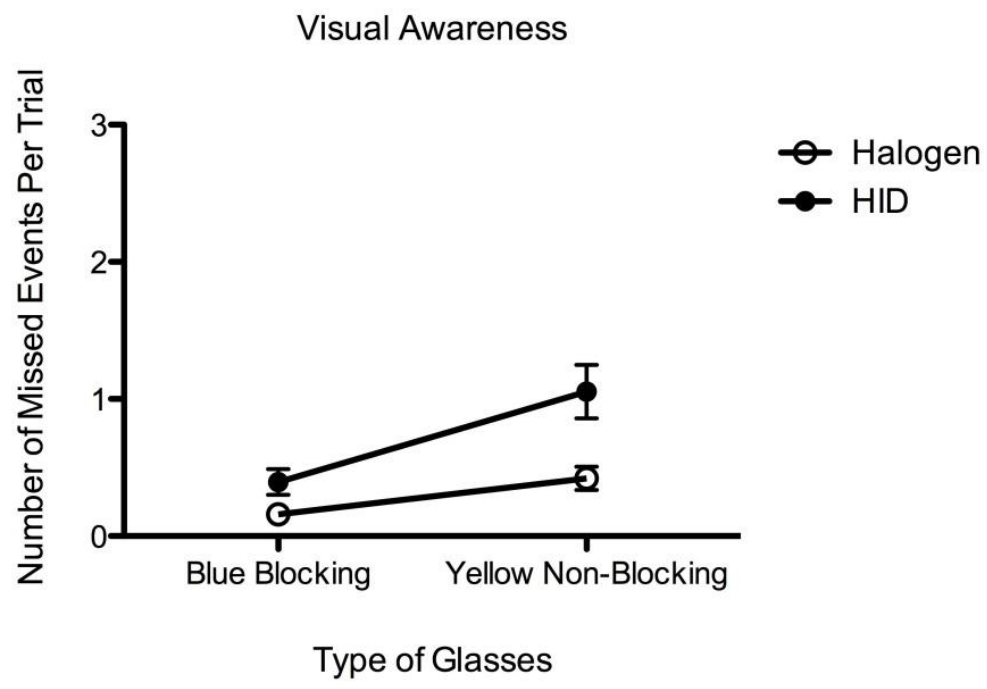

Figure 20. Two-way interaction between headlight type and use of headlight-blocking system during visual awareness task.

The third two way interaction between age and headlight type was not found to be significant $[F(1,69)=0.11, p=.747]$.

Lastly, the three way interaction between age, headlight type, and glare-blocking system was found to be significant $[F(1,69)=5.76, p=.019]$. This interaction suggests that for younger participants, the VA performance increase associated with use of the glare-blocking system is relatively equal for halogen and HID headlights. In essence, the glare-blocking system improves VA scores by nearly the same amount whether used for HID or halogen lights. In contrast, older adults had a disproportionate VA performance increase when using the glare-blocking system in conjunction with HID as compared to halogen headlights. In essence, while the glare blocking system improved older participants VA scores with halogen lights (with nearly the same improvement levels seen by the younger participants), when the glare-blocking system was used in 
conjunction with HID headlights a significantly elevated increase in VA performance was found (see Figure 21).

\section{Visual Awareness}

18-39

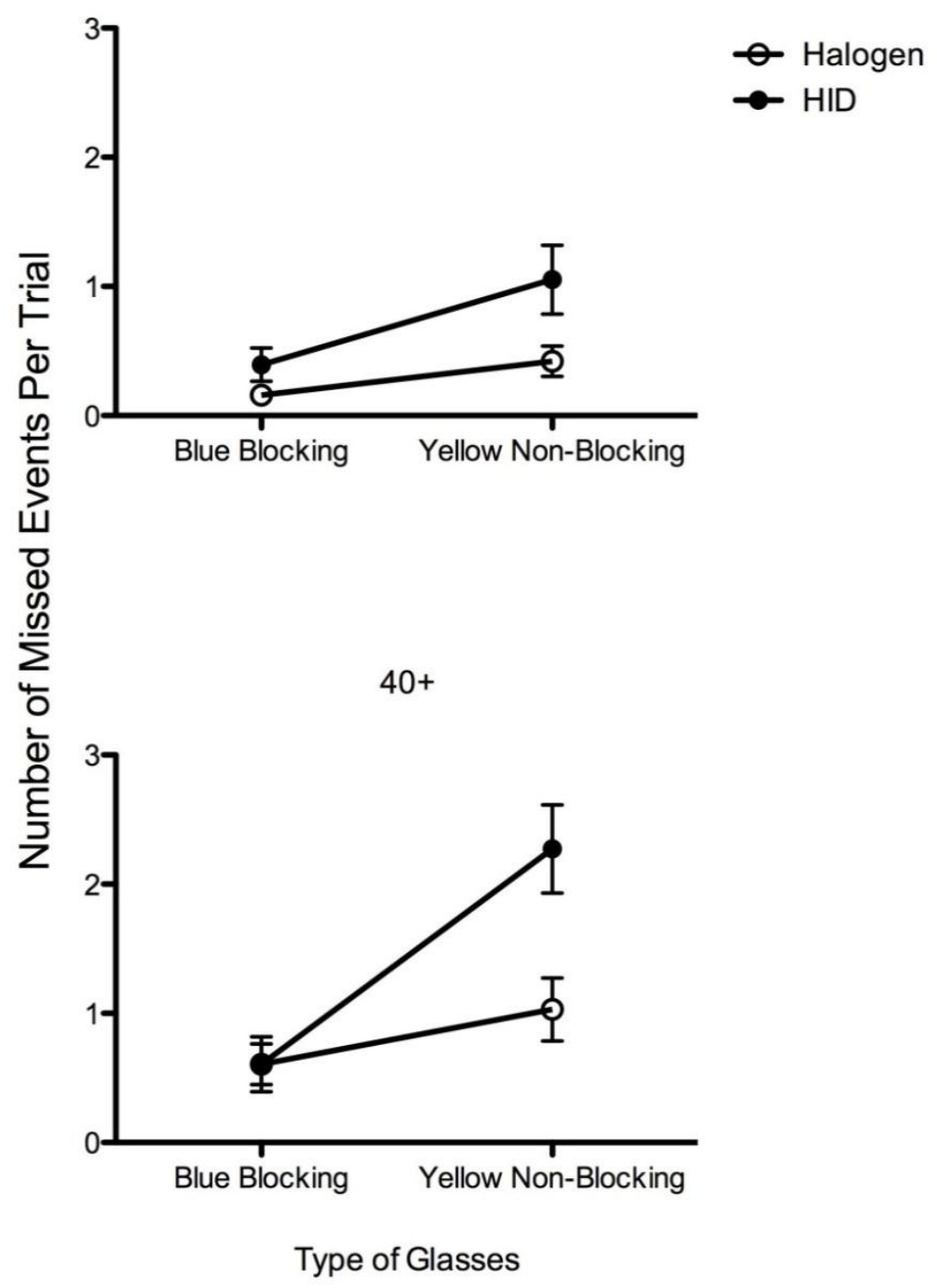

Figure 21. Three-way interaction for age, use of headlight-blocking system, and headlight type during visual awareness task. 
Stated simply, the glare-blocking system appeared to improve VA performance across all conditions, but was especially effective in improving performance for older adults when exposed to HID headlights. This disproportionate VA performance score increase, suggests that older drivers are especially susceptible to visual awareness errors under the extreme glare conditions caused by the HID headlights, but that with use of the glare-blocking system, HID headlights did not substantially reduce VA performance any more than did the halogen lights. Both groups saw overall visual awareness performance benefits associated with glare-blocking system usage.

\section{Visual Awareness - False Positive (VA-FP)}

No significant difference in VA-FP horn presses were found for headlight type $[F(1,57)=0.92, p=.342]$. The analysis yielded no significant difference in VA-FP when utilizing the head-mounted glare-blocking system $[F(1,57)=0.18, p=.667]$. Age was however found to be a significant factor influencing VA-FP events $[F(1,57)=4.59$, $p=.037]$, with drivers over 40 making more erroneous horn presses than their younger counterparts (see Figure 22). 
Visual Awareness FP

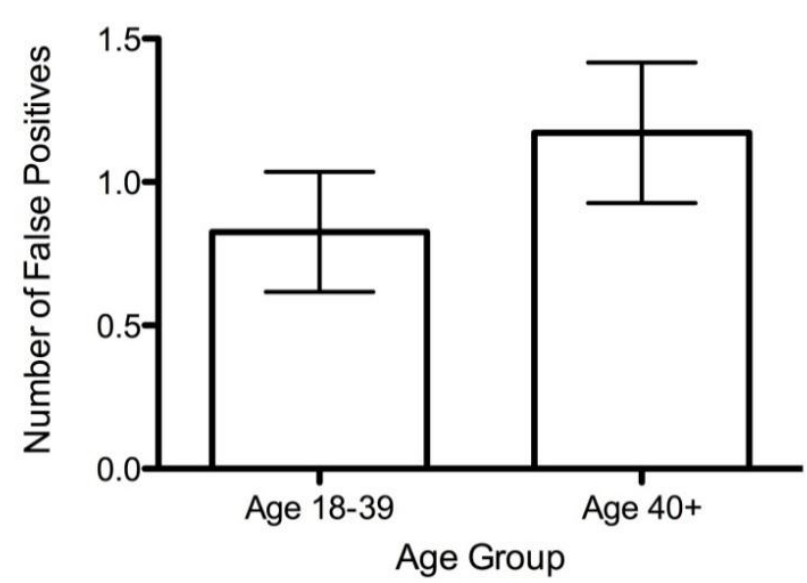

Figure 22. Differences in false-positive response rate for age groups during the visual awareness task.

No significant two-way interactions were found for VA-FP events between type of headlights and age $[F(1,57)=3.53, p=.065]$, type of headlights and glare-blocking system $[F(1,57)=0.08, p=.781]$, or age and glare-blocking system $[F(1,57)=0.01, p=$ .924]. Similarly, the three-way interaction between age, headlight type, and glareblocking did not yield significance for the VA-FP measure $[F(1,57)=1.25, p=.268]$. In summary, older participants were found to make significantly more erroneous horn presses than the younger participants. 
Table 1

Means for all variables and conditions.

\begin{tabular}{|c|c|c|c|c|}
\hline \multirow[b]{3}{*}{ Age Group } & \multicolumn{2}{|c|}{$\underline{\text { Glare-Blocking }}$} & \multicolumn{2}{|c|}{$\underline{\text { Non-Glare-Blocking }}$} \\
\hline & Halogen & $\underline{\mathrm{HID}}$ & Halogen & $\underline{\mathrm{HID}}$ \\
\hline & Mean $(S D) n$ & Mean $(S D) n$ & Mean $(S D) n$ & Mean (SD) $n$ \\
\hline \multicolumn{5}{|c|}{$\begin{array}{l}\text { Steering Performance } \\
\text { (SP) }\end{array}$} \\
\hline Younger & $15.73(5.88) n=37$ & $16.48(8.06) n=37$ & $15.02(5.38) n=37$ & $15.98(6.68) n=37$ \\
\hline Older & $22.64(8.43) n=31$ & $21.82(8.34) n=27$ & 24.87 (8.89) $n=32$ & $24.59(9.62) n=32$ \\
\hline \multicolumn{5}{|c|}{ Time-to-Brake (TTB) } \\
\hline Younger & $0.87(0.29) n=37$ & $0.86(0.21) n=37$ & $0.87(0.24) n=38$ & $0.90(0.22) n=38$ \\
\hline Older & $0.89(0.21) n=33$ & $0.93(0.18) n=26$ & $0.92(0.25) n=33$ & $0.93(0.18) n=33$ \\
\hline \multicolumn{5}{|c|}{ Time-to-Brake False- } \\
\hline \multicolumn{5}{|l|}{ Positive (TTB-FP) } \\
\hline Younger & 1.95 (3.39) $n=37$ & $1.84(2.83) n=37$ & $2.18(3.78) n=38$ & $1.82(3.30) n=38$ \\
\hline Older & $7.30(12.52) n=33$ & $3.85(7.09) n=26$ & $5.88(8.40) n=33$ & $5.30(7.50) n=33$ \\
\hline \multicolumn{5}{|c|}{ Visual Awareness (VA) } \\
\hline Younger & $0.16(0.44) n=38$ & $0.39(0.79) n=38$ & $0.42(0.72) n=38$ & $1.05(1.64) n=38$ \\
\hline Older & $0.61(0.90) n=33$ & $0.61(1.22) n=33$ & $1.03(1.40) n=33$ & $2.27(1.96) n=33$ \\
\hline \multicolumn{5}{|c|}{ Visual Awareness False- } \\
\hline \multicolumn{5}{|l|}{ Positive (VA-FP) } \\
\hline Younger & $0.85(1.10) n=34$ & $0.97(1.67) n=35$ & $0.60(1.06) n=35$ & $0.88(1.25) n=34$ \\
\hline Older & $1.47(1.92) n=32$ & $1.07(1.33) n=27$ & 1.29 (1.24) $n=31$ & $0.84(0.92) n=32$ \\
\hline
\end{tabular}




\section{Discussion}

\section{Overview}

HID headlights are proven to improve road visibility for the driver whose car is fitted with them; however, worries regarding the effects of the added glare imposed on oncoming traffic has been a recent topic of controversy (Department of Transportation, NHTSA, n.d.; NHTSA, 2007). The primary goal of this study was to ascertain what, if any, performance differences exist when drivers are exposed to oncoming HID and halogen headlights in a life-like driving simulator. The secondary goal of this study was to explore the possibility of partially restoring any performance losses due to glare exposure with the use of an oncoming headlight glare-blocking system. Lastly, this study examined differences in driving performance for two age groups and explored interactions between age, headlight type, and a glare-blocking system.

Although some faculties of driving performance such as time-to-brake (ability to react to the illumination of brake lights immediately in front of you) and steering performance (accuracy of lane keeping ability) were found to be unaffected by glare, the impact on visual awareness (ability to perceive objects in your field of vision) resulted in substantial performance losses. More specifically, increased glare levels significantly decreased visual field perceptual abilities (VA) for the majority of the participants tested. The amount of performance degradation in older drivers was especially affected by the heightened glare caused by HID headlights.

The utilization of the polarized glare-blocking system significantly improved visual awareness performance when compared to the control. Of even greater importance 
was the effect that the glare-blocking system had on the performance of older drivers during HID headlight exposure. The glare-blocking system not only improved older diver VA performance in all conditions, but in essence restored VA performance to levels resembling that of the younger drivers in same condition. The intensified performancelosses in the older drivers alone constitute a potential major safety concern. The significant visual performance losses exhibited by older drivers in this study warrant further investigation, as this group as a whole failed to respond to rather large and stationary objects appearing in their visual field. Although the extent of this negative effect was quite substantial, the use of the glare-blocking system virtually negated the ill effects of the headlight glare, while not impacting other measures of driving performance. In a real-world context, the glare-blocking system could potentially aid object recognition for a large percentage of the population, but would especially aid older drivers in seeing what would normally be obscured from their vision with oncoming HID headlights.

\section{Specific Glare Effects}

Performance on the visual field task changed significantly between differing conditions. Halogen headlight exposure resulted in significantly less visual field performance losses than HID headlights. The losses incurred with both types of headlights were, however, reduced with the use of the headlight glare-blocking system. In all scenarios, the use of the headlight blocking system resulted in the most accurate visual field performance. What this finding suggests is that drivers' awareness of objects in their visual field might be directly hindered by high levels of glare, and that, as the lighting levels increase, the ability to recognize the appearance of relatively large objects 
significantly decreases. Conversely, as the polarized glare-blocking system greatly reduced glare intensity, driver performance on the visual field awareness task was most accurate (even under halogen light exposure) when using system. This effect was especially pronounced in the older driver sample, under the heightened glare caused by HID headlights.

What might be the cause of this glare-induced reduction in perceptual ability, and why are other important measures of driving performance (which also rely on the visual system such as time-to-brake, and steering performance) not affected whatsoever? At first glance it is tempting to assume that headlight glare simply causes an overall reduction in visual acuity, or possibly reduced contrast ratio across the entire visual field. Mainster and Timberlake (2003) showed, however, that high levels of glare can, in fact, cause an overall decrease in contrast ratio across the visual field as stray light is refracted within the eye. Thus, the refraction may become worse with age as defects in the vitreous fluid, lens, and other portions of the eye may accumulate with time. This decreased contrast ratio caused by increased inner eye refraction may be one explanation for the significant decrease in visual field perception under HID headlight exposure, and could also partially explain the disproportionate negative effects on older drivers exposed to HID headlights. Although this may be a partial explanation for this decreased perceptual performance, it does not address the lack of effect on steering and braking.

This explanation does not speak to the disproportionate number of missed visual awareness events as compared to other measures of driving performance; however, it is important to note that VA events changed in location as compared to the steering 
performance and time-to-brake tasks which remained in a static location in the center of the screen. If one thinks of the display screen in terms of nine quadrants, the quadrant in the center of the screen required the most visual attention, as the optimal steering line and braking tasks were both located here, along with $1 / 9$ of the visual awareness events.

One possible explanation for these results may lie in a 'cognitive tunneling' effect. That is to say, when cognitive load demands increase, less important or immediate tasks are neglected in order to attend to the most crucial tasks at hand (Caserta \& Abrams, 2007). Glare could potentially cause cognitive resources to be diverted due to annoyance, distraction, pain, or simply added mental effort to process a more obscured visual scene. Because steering the car is a primary and fundamental task while driving, it is feasible that the act of steering may be more resilient to additional cognitive load caused by oncoming glare. Similarly, the time-to-brake task may not have required as much cognitive resources to monitor for color-change, as the braking events took place in a similar screen location to that of the steering task. In contrast, visual awareness events took place randomly around the screen, and occurred at random intervals. As a result, we might consider the act of scanning the visual field a secondary task. Visual awareness events were found in this study to be frequently missed in highglare scenarios, whereas they were less frequently missed in low-glare scenarios. If scanning the visual field is a secondary task and takes constant effort to monitor but occurs infrequently, participants may have been less likely to attend to this task when distracted by the effects of glare. If true, the effect of reduced VA performance could be a result of 'cognitive tunneling' during exposure to high levels of glare. 
The addition of the glare-blocking system improved VA performance, suggesting the possibility that during times of low glare (and theoretically lower cognitive demands) greater cognitive resources can be dedicated to scanning the visual field for the appearance of novel objects. This effect was significantly more pronounced for older drivers, and with exposure to HID headlights.

While a cognitive tunneling effect is a plausible explanation, it is also possible that the glare experienced by the participants directly resulted in visual degradation (disability glare) which obscured the VA events from being seen, or combination of both conditions. Disability glare (a decreased contrast ratio obscuring the visual scene) may have been a factor which lead to decreased VA performance, but could also increase cognitive load in itself, requiring more intense cognitive processing to parse a hazy or obscured image. Whether cognitive tunneling, an obscured visual image, or an interaction between both is responsible for the loss of VA performance, the end result is a potential roadway safety hazard due to broad failures to recognize large and stationary objects appearing in the visual scene. A real-world equivalent is akin to a deer suddenly appearing outside of the lane of travel, and a driver completely failing to perceive or respond to it. Similarly, an automobile in an adjacent lane could make an abrupt maneuver, and as a result of increased glare, the driver may fail to recognize the impending collision in time to take evasive action.

The current study suggests a visual (or mental) equivalent to wearing 'blinders' during exposure to oncoming HID headlights. As this effect is substantially more pronounced for older adults, their visual awareness performance is further restricted with 
an increase in potential accidents related to these performance losses. Thus, the findings in this study imply that a potential safety concern lurks on roadways today due to the steadily increasing use of HID lights in current production cars. Even more disturbing is the recent implementation of the next generation of LED based headlights which are far more efficient and have the potential to produce levels of light output far exceeding that of HID headlights.

\section{Comparative Findings}

The issue of driving performance under exposure to headlight glare is a complex issue with many variables. These include but are not limited to: headlight type, level of luminance, color, angle of exposure, beam pattern, weather and road conditions, headlight lens and windshield clarity, driver age, eye conditions, driver experience, roadway and vehicle lighting, and exposure duration. Because of the large numbers of variables involved, laboratory studies typically can only replicate a few of these variables at a time, however many of the aforementioned factors have the potential to significantly interact with each other. For instance, a driver suffering from cataracts will have a greatly increased level of intra-ocular light scatter, which is exacerbated by high levels of luminance (Babizhayev et al., 2009; Owsley et al., 2001). Moreover, a dirty windshield, headlight lens, rain, and fog also contribute to light scatter resulting in a decreased contrast image or loss of visual acuity. In isolation, the cataract patient with a clean windshield may show only moderate loss of visual acuity; however, compounding the situation with additional light scatter from a dirty windshield could seriously amplify the problem and create a severe loss of performance. As a result, a narrowly focused study 
may miss this significant interaction, which likely takes place in real-world driving conditions. The narrow focus of many current studies may be the source of conflicting findings suggesting oncoming headlight glare has little to no impact on driver performance.

Some researchers, such as Anderson and Holiday (1995), Balik (2010), and Bullough et al. (2002) found significant levels of discomfort glare associated with automobile headlights, but failed to find significant visual impairment. An examination of the methods of these studies found that participants were often only tested for foveated visual performance (one degree of visual angle in the utmost center of the visual field) or with fixed target locations. These findings are consistent with the current study in relation to tasks such as steering performance and time-to-brake (which were located in the center of the screen) which, in general, were not significantly impacted by glare exposure. The current study found, however, that performance on the visual awareness task was significantly impacted by glare exposure. This finding is in direct conflict with the aforementioned research. The performance discrepancy on this task may have been a result of the need for the participant to continuously scan their field of view to complete the visual awareness task (as would be required on an actual roadway), unlike the fixed targets in the previously mentioned research.

The notion that oncoming glare directly impacts non-central visual tasks is supported by Theeuwes et al. (2002) who used simulated headlights affixed to the hood of the subjects' vehicle, in a real-world driving environment while actually operating a vehicle. The authors found that even low levels of glare caused significant drops in the 
detection rates of simulated pedestrians on the side of the road. These losses were found to be substantially greater for older drivers. A complex driving environment not only requires more cognitive attention but also requires constantly moving eye gaze. It was suggested that when participants' eyes are not fixated on the location of the visual target, many visual stimuli that would otherwise be seen in a glare-free environment are missed. These findings both support and validate the findings of the current study.

Although some studies found differing levels of impact on driving performance itself (disability glare), most of the studies in this field do agree that oncoming headlights can cause discomfort glare, which is bothersome or distracting to many drivers. Simply the fact that glare is annoying (whether it directly affects driving performance or not) has sparked controversy and investigations into the issue by federal agencies such as the NHTSA (National Highway Traffic Safety Administration) who have gone so far as to bring the issue before congress (National Highway Traffic Safety Administration, 2007). The concern appears to be mirrored by the general public, as NHTSA has reported a massive increase in recent complaints regarding the glare caused by newer headlights to cause annoyance, pain, distraction, and even possible visual impairment (Department of Transportation, NHTSA, n.d.). These NHTSA reports suggest that glare caused by oncoming headlights (or reflection of headlights from the rearview or side mirrors) may lead to disability glare, or a level of glare that affects perceptual abilities. These recent articles further validate the findings of the current study, suggesting that increased glare caused by HID headlights have the ability to decrease visual awareness performance. 
HID headlights are a common topic of complaint, which is understandable as HID headlights produce two to three times the output intensity of standard halogen bulbs (Mainster \& Timberlake, 2003). It follows that a drastic spike in headlight output proportionately increases the amount of associated glare. A number of previous studies however have failed to find any ill effects of glare and deemed glare to be a nuisance but not a safety concern (e.g., Balk, 2010; Flannagan et al., 2000; Ranney et al., 1999).

In a recent doctoral dissertation examining the effect of glare on driver visual acuity, Balk (2010) concluded that glare from both halogen and HID headlights had no significant impact on driver performance. In addition, this study asserted an incompatibility between the participants' self-rated scores of discomfort, and actual performance-degrading effects under the same levels of glare. While the data collection methods from this study are not in question, the design of the study and the conclusions drawn from the data are in direct conflict with those of the current study.

Differences in methodology likely account for these conflicting findings. Participants sat in the passenger seat of a moving vehicle that was approached by another vehicle with headlights of varying types. Letter cards were placed to the side of the road, and the participant was asked to identify the letter under various oncoming glare conditions. Participants in this study had little problem accurately completing this task in all glare scenarios, and as a result the researchers concluded that glare levels from current headlights are not great enough to affect driving performance. This study fixed target location, where in a real world driving environment target location would be unknown. Concurrent tasks needed to operate a motor vehicle, such as steering for instance, were 
also not required as the participant sat in the passenger seat. With target location as their only task requirement, and participants allowed to actively look for targets in a known location, it was highly likely that peripheral vision was not needed to locate these targets. As mentioned previously, peripheral vision is most heavily impacted by glare (Owens et al., 2007). In other words, the tasks required of these participants differed dramatically from those required by drivers in a real world environment. In addition to these issues, the participants selected for this study were all young ( $M=20$ years old). As shown by previous literature, glare disproportionately affects older drivers significantly more so than the younger drivers. The conclusions drawn from this study and others like it may be misleading, suggesting that glare has no impact on driver performance.

A flaw in many laboratory studies regarding glare revolves around the issue of fixing the stimulus location, as well as participant anticipation of an upcoming stimulus. In real world driving, vehicle operators concurrently perform many tasks which draw attention away from events occurring in their peripheral visual field. Additionally, drivers are required to constantly scan their entire field of view for hazards whose location cannot be predicted (in contrast to some laboratory studies in which object location can be anticipated).

Further findings, contradictory to those of the current study, were reported by Flannagan et al. (2000). This night-time glare study found no objective performance differences for varying oncoming low-beam headlights and, as a result, concluded that no clear upper limit for headlight intensity exists. They noted that seeing distance is increased with greater headlight intensity, and that few downsides exist (aside from 
discomfort) when utilizing brighter headlights. Similar to the findings by Balk (2010), their findings also showed that subjective ratings of discomfort caused by glare increased with headlight intensity, but visual performance was not impacted. As mentioned previously, this study both lacked concurrent tasks, and utilized a fixed location for the visual recognition task. Without extraneous engaging tasks, and with only a single location for the visual stimulus to appear, participants had no trouble identifying the targets. These findings are consistent with the current study in relation to visual events appearing in the center of the screen (SP and TTB), however, the findings of Flannagan et al. (2000) do not address identification of objects in other locations in the visual field.

In the same article, Flannagan et al. (2000) suggest the utilization of brighter headlights as a mitigation strategy for oncoming glare. They explain that by decreasing the contrast ratio between the point source (oncoming headlights) and the background luminance (roadway illuminated by the brighter headlights of your own vehicle) glare can be diminished. This recommendation is simply fighting fire with fire because the same brighter headlights (when viewed as oncoming headlights from another car) would require an even further increase in the luminance level of the drivers' vehicle to reduce the contrast ratio of the oncoming lights. We currently have a growing percentage of cars with HID headlights on the road, despite a growing public consensus that they are uncomfortable, painful, or blinding (Bullough et al., 2008; NHTSA, 2007). Nevertheless, the demand for brighter headlights may be a consumer response to increase nighttime visibility, which has been degraded by the now brighter headlights of others. While the 
benefits of brighter headlights are obvious, the potential downsides must not be overlooked.

As average headlight intensity on public roadways is steadily increasing, it is important that roadway safety is not negatively impacted by these changes, and that no segment of the population (such as those with conditions that affect the functioning of the eye) is unreasonably burdened or affected by new headlight designs. Indeed, Owsley and McGwin (1999) found that segments of the population with mild-to-moderate eye conditions (of varying types) are more susceptible to vision-related accidents, and glare from oncoming headlights may make night driving an especially difficult task for these drivers. In their study, some of these drivers reported attempting to self-limit their driving at night to compensate for their decreased visual acuity. Given that driving is inexorably linked to mobility and daily functioning, many older drivers are unable to selflimit their driving times.

\section{Additional Age Effects}

Aside from the effects of glare, in the current study age was shown to play a significant role in steering performance. With the simulator used in this study, lanekeeping ability was lower for the older driver sample. Visual observation of older drivers' steering motions revealed more erratic motions and overcompensation of steering angle than younger drivers. These differences may simply be an artifact of the driving simulator itself or inherent in the older driver population. The driving simulator did not give as much steering feedback as would a road car, and steering angle versus virtual car movement was more linear of a relationship as compared to turning a steering wheel in a 
moving car. Younger drivers had little problem adapting to this steering response, and there is the possibility that vastly greater experience with video games and electronic devices between the two age groups may be a factor for these discrepancies. This area will require future study to investigate the cause of these discrepancies.

Another interesting age related finding in the current study was the lack of differences in average reaction time for younger and older drivers. This finding is contrary to research examining simple reaction time in the presence of glare by Smith and Brewer (1995), which suggests that reaction time itself should increase with age. Research by Wood et al. (2005) examining driving performance on a closed-circuit driving course found no significant reaction time difference between younger and older drivers, however. This finding is consistent with the results of the current study. The 'time to brake' measure took into account not only basic reaction time itself, but recognition of the object in addition to task switching time between concurrent tasks. As the lead car turned red, a participant was required to momentarily divert their attention from whatever they were currently engaged in (be that steering, scanning for visual field stimulus, or any number of other thought processes or actions) to momentarily attend to the braking task and press the brake pedal.

Simple average reaction time has been shown to increase with age (Smith \& Brewer, 1995), however, it appears that older drivers may possibly develop compensatory methods to combat the performance losses experienced with age. It may be that as we age and our reaction time decreases, we compensate by improving our ability to manage or switch between tasks. The brake pedal foot movement may even be 'pre-loaded' so 
that we may more quickly carry out the required action when the braking event is required. If this is the case, it may be a possible explanation for the significantly elevated false-positive inputs from older drivers in both the braking and visual field tasks. This suggested hypersensitivity or hyper-vigilance may be an effective method developed with age to compensate for decreased cognitive and/or perceptual abilities.

If these compensatory methods do exist for older drivers, they could potentially explain the increased rates of false positive brake pedal presses. These 'error responses' are significantly greater in older adults, and also decrease as light level increases with the brighter HID headlights. At first we may think of an input with no stimulus present as simply an 'error.' In actuality, however, these instances may be a measure of extraneous reactions caused by a 'hyper-sensitivity' to brake stimuli. If the proposed compensatory method (hypersensitivity or pre-loading of the brake response) is a valid explanation, older drivers may react more often to events partially resembling the stimuli for which they are scanning. It then follows that either disability glare (reducing contrast ratio) or discomfort glare (increasing cognitive load) may lead to the observed reduction in TTBFP responses under higher glare conditions. That is to say, as glare increases (and theoretically cognitive load), less cognitive resources are available to maintain the 'hyper-sensitivity' which normally exists in older drivers.

Are the decreased false-positive responses under high-glare simply 'errors' or a measure of hyper-sensitivity loss (a proposed compensatory method to counteract age related cognitive declines)? A decrease in time-to-brake performance does not appear to accompany this trend; however the proposed effect may not be strong enough to cause 
performance declines in the actual braking task itself. Granted, these responses may simply suggest that older drivers make more 'errors' (false positive responses) on the braking and visual field tasks, or even a switching of modalities causing them to press the horn when they meant to press the brake and visa-versa. At this stage the causes for increased false positives for the older age group are unclear. More research is needed to determine the causes of this effect.

An interesting phenomenon also occurred for older drivers regarding visual awareness false positive responses. VA-FP responses resulted when no visual field stimulus was present but the subject pressed the horn anyway. False positive responses for the visual field measure differed between younger and older drivers (independent of glare) with older drivers making more false positive presses than younger drivers. Like the erroneous brake presses, the horn presses with a lack of stimulus could be construed simply as increased 'errors' however they may also be a compensatory method similar to the one suggested above for the brake response. Again further research is needed to determine the cause of this effect.

\section{Limitations and Future Research}

A serious limitation of the proposed study is the extent to which glare from oncoming headlights can be simulated in a lab. In real-world driving situations, the type of oncoming headlights, speed of approach, duration of exposure, lens and windshield clarity, weather, and angle of headlights (on a hill, in a turn) may play a significant role in the perception of roadway glare. In addition to these, driver variables such as age, eye conditions, driver compensatory strategies (such as blocking glare with a hand, 
squinting), affect driver perception of glare and the resulting effect on driving

performance. Added to that, the many tasks that a driver must concurrently carry out are difficult to assess fully in a lab simulator. In this study, an attempt to control for as many extraneous variables was made while attempting to collect as much live data from the participants as possible. Future research may look at specific combinations of external variables such as driving in fog, or with a somewhat hazy windshield, as they interact with other known factors for night driving degradation such as with the presence of eye conditions. The current study focused on a highway-like driving scenario; however, it is also important to examine these same variables in rural environments as well as in city and suburban driving environments.

The current study was also limited in number of participants $(n=71)$ and age of participants ( $M=60$ years for older age group). Drivers with significant eye conditions such as cataracts would also be worthwhile to include in future research, as the results from the current study suggest that these individuals may be at a higher risk for visual degradation due to intraocular light scatter. Although this study included 'older' drivers, elderly drivers in their 80 s and up were not evaluated. As the elderly demographic is theoretically the most affected by glare, future research should specifically evaluate this cohort in comparison to 'older' and 'younger' drivers. Lastly, although we tested the current halogen and HID standards, it is of interest to investigate the effects of the next generation of LED-based headlights as they relate to oncoming glare. As the newer LED headlights are two-to-three times brighter than the HID headlights (which were shown to see significant performance degradation, especially for older drivers) it is imperative that 
these newer lights are tested in the immediate future to evaluate their impact on roadway safety.

\section{Implications for Practice}

Because older drivers are already more susceptible to visual degradation caused by glare (Sturgis \& Osgood, 1982), the addition of significantly brighter headlight systems may already be negatively impacting their driving abilities, leading to an increased potential for accidents. Further compounding the problem, the driving population is projected to make a major shift towards older drivers in the next 20 years, so that one fifth of the driving population will be 65 years of age or older by 2030 (Gray \& Regan, 2007). For these reasons, it is imperative that researchers, car companies, and legislators better assess the extent of the problem.

Some researchers have advocated for increased driving tests for glare susceptibility, but as Charman (1997) noted the current methods available to screen for glare impairment in older drivers will also eliminate a large percentage of older drivers as well as younger and quite capable drivers. Sturgis and Osgood (1982) also suggested that a night-driving test could be created, but the lighting levels for the test would need to be finite. Currently, lighting levels of cars (such as produced by HID and soon LED headlights) are increasing in intensity, and a test would need to be constantly updated with the most recent advances in lighting technology to replicate the worst case scenario. They argued that the more intense the test lighting levels are, the more drivers would fail, limiting the mobility of more and more drivers with increased light intensity. Both these research findings suggest that the solution may lie more in decreasing glare, as opposed 
to restricting drivers' licenses for the individuals who may be vulnerable to it. It is not the case that the average driver's eyes are becoming worse, but that new lighting technology is directly creating impairment for those who typically would not be impaired.

It is important to mention that as certain distinct populations of drivers become specifically targeted (such as older drivers risking the loss of a driver's license) a potential pushback from these affected groups may ensue. If the situation continues to worsen in the future, older drivers who are put at greater risk during nighttime driving may attempt to ban together and invoke the Americans with Disabilities Act to stop a dangerous situation that directly and disproportionately creates an unsafe situation for largest growing demographic on public roadways. As lighting technology progresses further (leaving the issue of glare relatively unchecked), groups of older drivers may attempt to force a stricter limit on headlight levels causing glare if it begins to restrict their mobility or hours of safe operation for motor vehicles. The average oncoming lighting level (from increasing use of HID, and now LED headlights) is substantially brighter than that of halogen headlights from less than a decade ago, and the situation only appears to worsen with each new introduction of headlight technology. Further advanced in headlight technology may make laser based headlights a reality in the future, and with nearly twice the efficiency per watt as LED headlights and a potential 1000x lumen output increase, a vastly more dangerous situation may lie ahead in the future.

The optimal solution for addressing the visual limitations of older drivers (as well as for the general public) is to increase headlight intensity while diminishing glare 
(Bullough, 2002); however, those two objectives are diametrically opposed. A glarereduction system, such as the one examined in this study (using polarized filters over headlights in conjunction with a polarized windshield or driver worn glasses) would serve the opposing goals of increasing light while reducing glare. In addition to the benefits of reducing glare from oncoming headlights, cross-polarized filters could be added to side mirrors, rear view mirrors, or rear windows to reduce glare caused by cars in back of the drivers' vehicle. Rear and side mirror glare have also been suggested as a potential source of visual degradation by the NHTSA (2007).

Potential hurdles exist in implementing a polarized glare-blocking system. As the polarizing filter type used in this study (and suggested for coating vehicle glass and mirrors) reduced light transmittance to approximately $43 \%$, concerns regarding a reduction in lighting of the roadway (as seen through the windshield for example) are valid. The reduced light transmittance may be accounted for however by simply increasing vehicle headlight output. Alternatively, a less efficient polarizer could be used to increase light transmittance. Most likely daytime light transmittance levels would only benefit from the polarized filter as many drivers already wear sunglasses to reduce light transmittance during the day, possibly reducing or eliminating the need for sunglasses. Additionally, as polarized filters have the ability to substantially reduce reflections (especially from glossy surfaces such as other cars) daytime glare could potentially be reduced as well. Further concerns may exist regarding the nighttime visibility of oncoming cars, as light transmittance of oncoming headlights (as viewed from other vehicles) has the potential to be reduced to as little as $.05 \%$ of the original output. A 
simple solution would be to increase the intensity of dedicated marker lights on the oncoming vehicle which would not utilize a polarized filter, and therefore not blocked by the system.

The implementation of a polarized system would require all car headlights to be fitted with polarized filters. Polarized lighting filters could be implemented either by car manufacturers as original equipment on new vehicles or as an aftermarket film added to headlight lens and windshields in a similar fashion to window-tinting laminate. As a side effect, polarized filters on windshields have been shown to significantly reduce daytime glare caused by the sun, especially in late day with angles of low sun (Japuntich, 2001). With a polarized (or similar) glare-reduction system, drivers can not only experience the safety benefits of increased roadway lighting, but at the same time significantly reduce glare associated with these brighter headlights which appear to negatively affect oncoming drivers considerably.

\section{Closing Remarks}

During nighttime driving, headlights are used to enhance our vision of the road and the visual scene in front of us. Unfortunately, what enhances the vision of one driver has the potential to degrade the vision of other drivers traveling in the opposite direction. The overall body of research in this field suggests that glare causes driving performance losses and that older drivers are especially susceptible. It goes without saying that visual acuity is important in the act of driving. It is our duty as automotive designers, researchers, and engineers to make absolutely certain that we do not negatively affect driver safety while at the same time continuing to improve vehicle performance. 
Anti-lock brakes, airbags, traction control, seat belt pre-tensioners, collision warning systems, and tire pressure monitors are just a handful of the recent safety developments aiding the modern day driver and mitigating various risk factors. These safety features are rarely used by the average driver, but when they are needed they have the potential to prevent a collision and possibly save lives. Countless hours of research and development went into developing these devices that are active only for an immensely small percentage of the vehicle operating time. A system such as a glareblocking system has the potential for improving nighttime vision for all drivers, thereby reducing the potential for accidents. A polarized glare-blocking system such as the one examined in this study would have low research and development costs while aiding driver safety and improving the driving experience. 


\section{REFERENCES}

Aguirre, R. C., Colombo, E. M., \& Barraza, J. F. (2008). Effect of glare on simple reaction time. Journal of the Optical Society of America A (JOSSA A), 25, 17901798.

Anderson, S. J., \& Holliday, I. E. (1995). Night driving: effects of glare from vehicle headlights on motion perception. Ophthalmic and Physiological Optics, 15, 545551.

Babizhayev, M. A., Minasyan, H., \& Richer, S. P. (2009). Cataract halos: a driving hazard in aging populations. Implication of the Halometer DG test for assessment of intraocular light scatter. Applied Ergonomics, 40, 545-553.

Balk, S. A. (2010). The accuracy of observers' estimates of the effect of glare on nighttime vision: Do we exaggerate the disabling effects of glare? (Doctoral dissertation, Clemson University, 2010). Dissertation Abstracts International, 71, 5.

Bullough, J., Fu, Z., \& Van Derlosfske, J. (2002). Discomfort and Disability Glare from Halogen and HID Headlamp Systems. SAE World Congress, Detroit, Michigan.

Bullough, J., Skinner, N., Pysar, R., Radetsky, L., Smith, A., \& Rea, M. (2008). Nighttime glare and driving performance: Research findings. NHTSA Report No. DOT HS 811 043. Washington, D.C.: U.S. Department of Transportation. http://www.nhtsa.dot.gov/staticfiles/DOT/NHTSA/NRD/Multimedia/PDFs/C rash\%20Avoidance/2008/811043.pdf 
Caserta, R. J., \& Abrams, L. (2007). The relevance of situation awareness in older adults' cognitive functioning: A review. European Review of Aging and Physical Activity, 4, 3-13.

Charman, W. N. (1997). Vision and driving-a literature review and commentary. Ophthalmic and Physiological Optics, 17, 371-391.

Department of Transportation, National Highway Traffic Safety Administration. Glare from Headlamps and other Front Mounted Lamps: Request for Comments(n.d).(Docket No. 01-8885: Notice 01.) Retrieved March 1, 2012, from http://www.nhtsa.gov/cars/rules/rulings/glare.html

Fekete, J., Sik-Lányi, C., \& Schanda, J. (2006). Spectral discomfort glare sensitivity under low photopic conditions. Ophthalmic and Physiological Optics, 26, 313317.

Flannagan, M. J., Sivak, M., Traube, E. C., \& Kojima, S. (2000). Effects of overall lowbeam intensity on seeing distance in the presence of glare. Transportation Human Factors, 2, 313-330.

Flannagan, M. J., Sullivan, J. M., \& Schoettle, B. (2008). Evaluation of recent US tungsten-halogen and HID headlamps using CHESS. University of Michigan, Transportation Research Institute.

Franssen, L., Tabernero, J., Coppens, J. E., \& van den Berg, T. J. T. P. (2007). Pupil size and retinal straylight in the normal eye. Investigative ophthalmology \& visual science, $48,2375-2382$. 
Gray, R., Perkins, S. A., Suryakumar, R., Neuman, B., \& Maxwell, W. A. (2011). Reduced effect of glare disability on driving performance in patients with blue light-filtering intraocular lenses. Journal of Cataract \& Refractive Surgery, 37, 38-44.

Gray, R., \& Regan, D. (2007). Glare susceptibility test results correlate with temporal safety margin when executing turns across approaching vehicles in simulated lowsun conditions. Ophthalmic and Physiological Optics, 27, 440-450.

Hoffman, L., McDowd, J. M., Atchley, P., \& Dubinsky, R. (2005). The role of visual attention in predicting driving impairment in older adults. Psychology and aging, $20,610-622$.

Japuntich, D, (2001). Polarized task lighting to reduce reflective glare in open-plan office cubicles. Applied Ergonomics, 32, 485-499.

National Highway Traffic Safety Administration (2007). Nighttime Glare and Driving Performance: Report to Congress. http://www.nhtsa.gov/DOT/NHTSA/NRD/Multimedia/PDFs/Crash\%20Avoidanc e/2007/Glare_Congressional_Report.pdf

Mainster, M., \& Timberlake, G. (2003). Why HID headlights bother older drivers. British Journal of Ophthalmology, 87, 113-117.

Owens, D. A., Wood, J. M., \& Owens, J. M. (2007). Effects of age and illumination on night driving: A road test. Human Factors: The Journal of the Human Factors and Ergonomics Society, 49, 1115-1131. 
Owsley, C., \& McGwin Jr, G. (1999). Vision impairment and driving. Survey of Ophthalmology, 43, 535-550.

Owsley, C., Stalvey, B. T., Wells, J., Sloane, M. E., \& McGwin Jr., G. (2001). Visual risk factors for crash involvement in older drivers with cataract. Archives of Ophthalmology, 119, 881-887.

Poot, L., Snippe, H., \& Van Hateren, J. (1997). Dynamics of adaptation at high luminances: adaptation is faster after luminance decrements than after luminance increments. Journal of the Optical Society of America: A (JOSA A), 14, 24992508.

Pulling, N. H., Wolf, E., Sturgis, S. P., Vaillancourt, D. R., \& Dolliver, J. J. (1980). Headlight glare resistance and driver age. Human Factors: The Journal of the Human Factors and Ergonomics Society, 22, 103-112.

Ranney, T. A., Simmons, L. A., \& Masalonis, A. J. (1999). Prolonged exposure to glare and driving time: effects on performance in a driving simulator. Accident Analysis \&amp; Prevention, 31, 601-610. doi: 10.1016/s0001-4575(99)00016-0

Ratcliff, R. (1993). Methods for dealing with reaction time outliers. Psychological Bulletin, 114, 510-532.

Rumar, K. (2000). Relative merits of the US and ECE high-beam maximum intensities and of two-and four-headlamp systems. Transportation Research Institute, University of Michigan at Ann Arbor (Report No.UMTRI-2000-41) http://hdl.handle.net/2027.42/49438 
Smith, G. A., \& Brewer, N. (1995). Slowness and age: Speed-accuracy mechanisms. Psychology and Aging, 10, 238-247.

Sturgis, S. P., \& Osgood, D. J. (1982). Effects of glare and background luminance on visual acuity and contrast sensitivity: implications for driver night vision testing. Human Factors: The Journal of the Human Factors and Ergonomics Society, 24, 347-360.

Theeuwes, J., Alferdinck, J. W. A. M., \& Perel, M. (2002). Relation between glare and driving performance. Human Factors: The Journal of the Human Factors and Ergonomics Society, 44, 95-107.

U.S. Department of Transportation: Federal Highway Administration (2011). Licensed Drivers by Age and Sex. Available from Federal Highway Administration Web site, http://www.fhwa.dot.gov/onhim/onh00/onh2p4.htm

Whetsel, S. (2011) The accuracy of drivers' perceptions on the effects of headlight glare on their ability to recognize pedestrians at night. Unpublished master's thesis, Clemson University, Clemson, South Carolina.

Wood, J. M. (2002). Age and visual impairment decrease driving performance as measured on a closed-road circuit. Human Factors: The Journal of the Human Factors and Ergonomics Society, 44, 482-494.

Wood, J. M., Tyrrell, R. A., \& Carberry, T. P. (2005). Limitations in drivers' ability to recognize pedestrians at night. Human Factors: The Journal of the Human Factors and Ergonomics Society, 47, 644-653. 


\title{
APPENDIX A: Consent Form
}

\section{Agreement to Participate in Research}

\author{
Responsible Investigator: Heath Friedland (HF/E Grad. Student) \\ Title of Protocol: Effectiveness of Glare Obscuring Glasses on Nighttime Driving Performance
}

1. You have been asked to participate in a research study investigating how headlight glare affects driving ability at night.

2. You will be asked to sit in a stationary experimental car, and use the steering wheel, brake pedal, and horn to interact with a visual display which will be projected on a screen in front of you. You will be asked to wear two sets of polarized glasses, and will be exposed to glare from standard automobile headlights. A score based on your performance with the visual stimulus will be logged on a computer along with video recordings of your session. This study will occur in room 194 in the engineering building on the San Jose State University campus.

3. You may experience slight discomfort from the oncoming glare if you are particularly sensitive to glare.

4. No direct benefit to subjects are expected, however your participation in this study may potentially contribute to improved technology which may increase nighttime driving safety.

5. Although the results of this study may be published, no information that could identify you will be included.

6. No compensation for participation in this study will be granted, aside from course credit to eligible Psychology students.

7. Questions about this research may be addressed to:

Heath Friedland

(510) 459-8956

firewire5@hotmail.com

Complaints about the research may be presented to:

Dr. Freund HF/E Program Chair

Department of Industrial \& Systems Engineering

(408) 924-3890

Ifreund@email.sjsu.edu

Questions about a research subjects' rights, or research-related injury may be presented to:

Pamela Stacks, Ph.D.

Associate Vice President, Graduate Studies and Research

(408) 924-2427.

8. No service of any kind, to which you are otherwise entitled, will be lost or jeopardized if you choose not to participate in the study.

9. Your consent is being given voluntarily. You may refuse to participate in the entire study or in any part of the study. You have the right to not answer questions you do not wish to answer. If you decide to participate in the study, you are free to withdraw at any time without any negative effect on your relations with San Jose State University.

- $\quad$ Please keep a copy of this form for your own records. By agreeing to participate in the study, it is implied that you have read and understand the above information. Please do not write any identifying information on the survey/questionnaire.

$\overline{\text { Investigator's Signature }} \overline{\text { Date }}$


APPENDIX B: Data Collection Forms

Your participant number is

Demographics:

- Do you have a valid driver's license? Y / N

- Age:

- Gender: M/F

- Do you wear corrective/prescription eyewear? Y/ N

(if yes, do you wear corrective/prescription eyewear when driving?) $\mathrm{Y} / \mathrm{N}$

Please list any visual problems you experience, or have been diagnosed with:

You will be using a driving simulator (game) on a projector screen, while sitting in a real car. You will be using only the steering wheel, brake, and horn. Please adjust the seat so that you are in a comfortable driving position. There are two sets of glasses, yellow and blue. Please put on the appropriate set of glasses when instructed.

You are welcome to do as many practice laps to get comfortable with the steering of the car. After you feel comfortable, you will do four testing laps which last about 3 minutes each. Please drive to the best of your ability. You will be doing three simultaneous tasks that occur in every day driving:

Steering: Your "car" is following the lead car in front of you. You are not the green car that you see on the screen, but are in a car driving behind them. Do your best to keep the car centered in the middle lane. There is a blue line in the road which represents the center of the lane.

Braking: The green car (which you are following) will turn from green to red quickly (and the screen will flash red as well). Please press the brake pedal in your car as quickly as you can. This tests your reaction time, so please press the brake as quickly as possible after seeing the car in front turn red. 
Honking: A cartoon squirrel will pop up on the screen, randomly in different locations. When you see the squirrel pop up, simply honk the horn of the car.

Glasses - Inside the car in the center console there are two sets of glasses (one yellow set, one blue set). We will let you know when to put the glasses on.

Article I. $\quad$ Exit survey

1. Did you prefer a particular set of glasses?

\begin{tabular}{|c|c|}
\hline Blue & 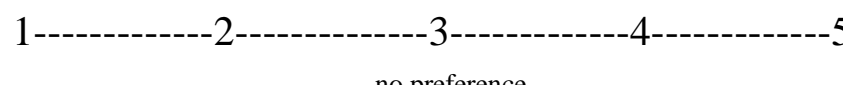 \\
\hline
\end{tabular}

Why? (optional)

2. Did you have a preference for the type of oncoming headlights?

H.I.D.

(bluer/whiter hue)

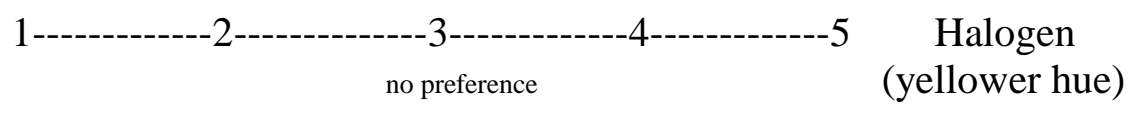

Why? (optional)

3. Do you ever specifically avoid driving at night? (If so, for what reason(s))

Yes No

4. Would you consider yourself "sensitive" to bright lights?

Sensitive 1--------2---------3--------4--------5 Not Sensitive 
5. Do you ever exhibit atypical driving practices to combat glare at night? (ex: wearing sunglasses, heavily squinting, attempt to block lights with your hand, etc.)

\section{Yes No}

If so, please explain (optional)

6. It's 5 years in the future, and you are in the market for a new car. If headlightblocking technology was available, how much would you be willing to pay for that option? (\$0 - \$2000)

$\$$

7. Would you use a headlight-blocking system that required you to wear glasses to experience the blocking effect?

$$
\text { Yes No }
$$

comments (optional)

Any final thoughts you wish to share about the study or your experiences with headlight glare? (optional)

Thank you for your participation in the study!! Seriously, we hope that you not only had fun, but also are happy to know that your participation and input may help to improve the future of driving safety and comfort.

**If you would like to recommend participation in this study to friends or colleagues, we ask you to please refrain from discussing how $\underline{\text { YOU }}$ perceived the effect of the glasses, so that we may collect unbiased opinions from every participant.** 


\section{APPENDIX C: Human Subjects Institutional Review Board Approval}

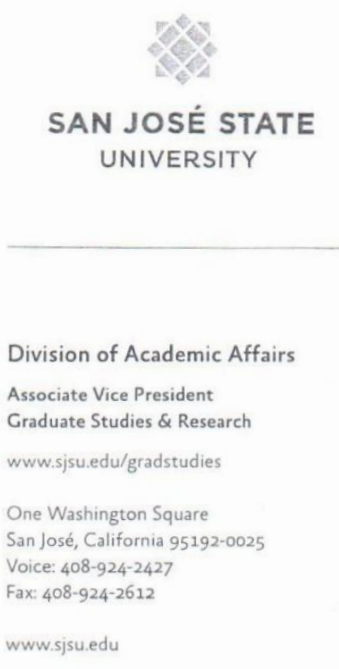

To: Heath Friedland

From: Pamela Stacks, Ph.D. Associate Vice President Graduate Studies and Research

Date: July 2, 2010

The Human Subjects-Institutional Review Board has approved your request to use human subjects in the study entitled:

\author{
"Effectiveness of Glare Obscuring Glasses on Nighttime Driving \\ Performance"
}

This approval is contingent upon the subjects participating in your research project being appropriately protected from risk. This includes the protection of the anonymity of the subjects' identity when they participate in your research project, and with regard to all data that may be collected from the subjects. The approval includes continued monitoring of your research by the Board to assure that the subjects are being adequately and properly protected from such risks. If at any time a subject becomes injured or complains of injury, you must notify Dr. Pamela Stacks, Ph.D. immediately. Injury includes but is not limited to bodily harm, psychological trauma, and release of potentially damaging personal information. This approval for the human subject's portion of your project is in effect for one year, and data collection beyond July 2, 2011 requires an extension request.

Please also be advised that all subjects need to be fully informed and aware that their participation in your research project is voluntary, and that he or she may withdraw from the project at any time. Further, a subject's participation, refusal to participate, or withdrawal will not affect any services that the subject is receiving or will receive at the institution in which the research is being conducted.

If you have any questions, please contact me at (408) 924-2427.

Protocol \#S1002191

cc. Louis Freund 0085 